\title{
Evaluation of Chitin-Glucan Complex Production in Submerged Culture of Medicinal Mushroom of Schizophilum commune: Optimization and Growth Kinetic
}

Mohaddeseh Zeynali ${ }^{1}$, Ashrafalsadat Hatamian-Zarmi ${ }^{*}$, Mohaddeseh Larypoor ${ }^{1}$

1. Department of Biology, Faculty of Bio Sciences, Tehran North Branch, Islamic Azad University, Tehran, Iran

2. Department of Life Sciences Engineering, Faculty of New Sciences and Technologies, University of Tehran, Tehran, Iran

\section{ABSTRACT}

Background: Schizophyllum commune, is one of the important medicinal-fungi foods in the world. Due to its important constituents such as extracellular and intracellular polysaccharides, it is widely used in industry and medicine. One of the important polysaccharides of this fungus is chitin-glucan complex (CGC). The aim of this study was to investigate the growth of native fungus Schizophyllum commune isolated from northern forests of Iran and to optimize its CGC production in submerged cultivation.

Materials \& Methods: Growth kinetics studies of native Schizophyllum commune fungi of Iran and CGC production were performed and growth curves were plotted. In order to increase CGC production, optimization of culture medium was done by investigating independent variables of $\mathrm{pH}$, inoculum percentage and aeration percentage by response surface methodology.

Results: The results showed that the specific growth coefficient of Iranian native Schizophyllum commune $\left({ }_{\max } \mu\right)$ was 0.991 day. Tenth day was also selected as the best time for growth and production in the submerged medium. In optimum conditions, initial pH of 8.92, percentage of inoculum 9.99 and aeration percentage of 150 was obtained. After 10 days, the amount of dry cell weight was $13.05 \mathrm{~g} / \mathrm{L}$ and the amount of chitin-glucan complex produced was $2.9 \mathrm{~g} / \mathrm{L}$.

Conclusion: Investigation of kinetic parameters of growth and production showed that the experimental data are in accordance with the logistic growth model with R2=0.9665 and the Luedeking and Piret model for production with R2 = 0.9439. The results also show that the initial $\mathrm{pH}$ has a significant effect on the growth of this fungus.

Keywords: Schizophyllum commune, Chitin glucan complex, Optimization, Submerged Cultivation

Received: 2019/11/29; $\quad$ Accepted: 2019/12/20; Published Online: 2020/01/10

\begin{tabular}{|c|c|}
\hline Corresponding Information: & $\begin{array}{l}\text { Ashrafalsadat Hatamian-Zarmi, Department of Life Sciences Engineering, Faculty of New Sciences and Technologies, University } \\
\text { of Tehran, Tehran, Iran. Email: hatamian_a@ut.ac.ir }\end{array}$ \\
\hline (c) (1) (8) & $\begin{array}{l}\text { his is an original open-access article distributed under the terms of the Creative Commons Attribution-noncommercial } 4.0 \text { International License, which } \\
\text { distribution of the material just in noncommercial usages with proper citation. }\end{array}$ \\
\hline
\end{tabular}

Use Mobile to scan and read the article online

Zeynali M, Hatamian-Zarmi A, Larypoor M. Evaluation of Chitin-Glucan Complex Production in Submerged Culture of Medicinal Mushroom of Schizophilum commune: Optimization and Growth Kinetic. Iran J Med Microbiol. 2019; 13 (5) :406-424

Download citation: BibTeX | RIS | EndNote | Medlars | ProCite | Reference Manager | RefWorks
Send citation to:
8 Mendeley
2 Zotero
Eit RefWorks

\section{Introduction}

In recent years, various metabolites such as, chitin, chitosan and CGC have been prepared from Schizophyllum commune due to their antibody properties and antiviral activity and have been used in pharmaceutical, cosmetic and hygienic fields (8،9). $S$. commune is a fungal and edible fungus belonging to the basidiomycetes family (14). CGC is a major component of the cell wall in yeast and fungi that stabilizes and strengthens cells and is a copolymer of diglucosamine, $\mathrm{N}$ acetylglucosamine, and glucose $(2,1)$. In 2010, Hao et al. investigated the optimization of variables affecting the growth and production of $S$. commune polysaccharide (17). Chagas et al. (2014) investigated the effect of $\mathrm{pH}$ and temperature on the production of CGC from the 
yeast Pichia pastoris (2). The purpose of this study was to investigate the variables affecting the growth of native $S$. commune fungi in Iran and increasing the production of CGC using response surface methodology and growth kinetic model And CGC production using Logical and Luedeking and Piret model.

\section{Materials and Methods}

\section{A) Cultivation Schizophyllum commune and CGC Extraction}

The fungus was cultured in culture medium PDB for 10 days. Then $2 \mathrm{~g}$ of dried mycelium was mixed with 60 $\mathrm{mL}$ of $4.2 \mathrm{~mol} \mathrm{NaOH}$. This mixture was incubated at $90^{\circ} \mathrm{C}$ for $3 \mathrm{~h}$. The mixture was centrifuged. The precipitate was then dissolved in $300 \mathrm{~mL}$ of sterilized distilled water and centrifuged again. The process was continued until $\mathrm{pH}=7$. The precipitate was then mixed with $60 \mathrm{~mL}$ of $0.25 \mathrm{~mol}$ $\mathrm{HCl}$ and placed in a $50^{\circ} \mathrm{C}$ oven for $2 \mathrm{~h}$. The precipitate was then mixed with $60 \mathrm{~mL}$ of $0.25 \mathrm{~mol} \mathrm{HCl}$ and placed in the incubator at $50^{\circ} \mathrm{C}$ for $2 \mathrm{~h}$. The precipitate was dissolved in $300 \mathrm{~mL}$ of distilled water and continued until $\mathrm{pH}=7$. CGC was dehydrated with isopropanol and placed at $60^{\circ} \mathrm{C}$ for $24 \mathrm{~h}$ (18).

\section{B) Experiment Design}

Response surface methodology was used to estimate the effect of independent variables on cell mass growth and CGC production of $S$. commune. The parameters affecting the production of $\mathrm{CGC}(\mathrm{pH}$, aeration percentage, percentage of primary inoculum) of $S$. commune were designed based on the BBD method (Box Behnken Design) of Design Expert 11 software.

C) Investigation of Growth Kinetics and Production of CGC for Schizophyllum commune

To obtain the growth curve of $S$. commune, this fungus was cultured in PDB medium for a period of 20 days and biopsy was performed every two days and biomass and CGC were recorded (22).

$$
\mathrm{dC} / \mathrm{dt}=\mu_{\mathrm{m}}\left(1-\mathrm{C} / \mathrm{C}_{\mathrm{m}}\right) \mathrm{C}
$$

Equation 1

In Equation 2, cell viability ( $\mathrm{gr} / \mathrm{L}$ ), $\mu_{\mathrm{m}}$ is the maximum specific growth rate (in terms of day $^{-1}$ ) and $C_{m}$ of the maximum cell mass concentration obtainable (gr/L). This equation is widely used to predict metabolites.

$$
(d P) / d t=\alpha(d C) / d t+\beta C
$$

Equation 2

Here $P$ is the concentration of CGC $(\mathrm{gr} / \mathrm{L}), \mathrm{C}$ the cell mass $(g r / L), \alpha$ in $\beta,\left(g \times g^{1}\right)$ in $\left(g \times(g \times h)^{-1}\right)$ values are constant. This model is experimental in which $\mathrm{dC} / \mathrm{dt}$ indicates CGC production rate relative to growth rate and $C$ represents CGC production regardless of growth.

\section{Results}

\section{A) Optimization of Parameters Affecting CGC Production}

Table 1 shows the results of cell dry weight and CGC values produced in each of the 17 experiments by combining different levels of parameters.

Analysis of variance of the results of the experiments in terms of cell mass and CGC level using Design Expert software is shown in Tables 2 and 3, respectively. $R^{2}$ values for cell dry weight and CGC were $9653 \%$ and $0.9584 \%$ respectively indicating a good correlation coefficient. According to software analysis based on dry weight of biomass produced, aeration percentage and $\mathrm{pH}$ with $\mathrm{P}$-values of 0.0097 and $<0.0001$, respectively and based on CGC weighted values of 0.0149 and $<0.00011$, respectively it had a significant effect on biomass growth and CGC. According to this analysis, there is no interaction between the variables studied. Also, the second power of $\mathrm{pH}$ variable with $\mathrm{P}$ - value of 0.009 and 0.0023 had significant effect on growth rate of biomass and CGC production, respectively.

Table 1. Experimental Design (BBD) and Results Based on Cellular Dry Weight and CGC Amount

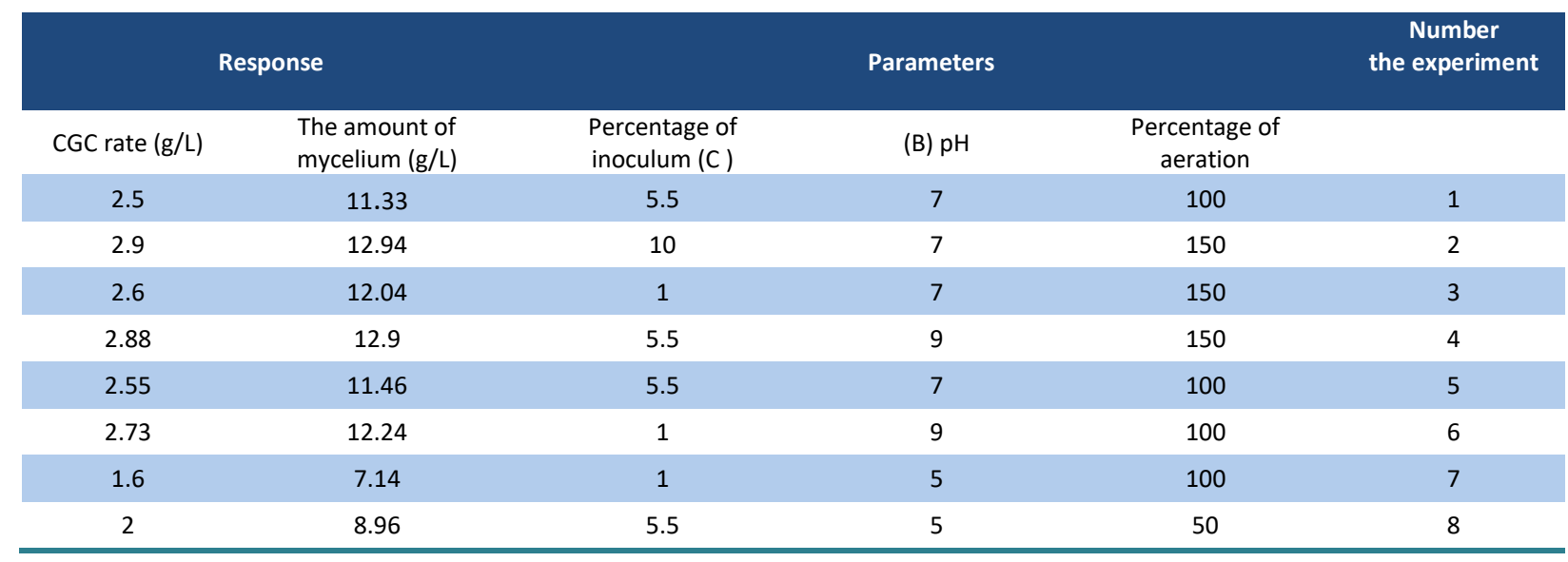




\begin{tabular}{|c|c|c|c|c|c|}
\hline \multicolumn{2}{|c|}{ Response } & \multicolumn{3}{|c|}{ Parameters } & \multirow{2}{*}{$\begin{array}{c}\text { Number } \\
\text { the experiment } \\
9\end{array}$} \\
\hline 2.6 & 11.68 & 5.5 & 9 & 50 & \\
\hline 2.2 & 10.1 & 1 & 7 & 50 & 10 \\
\hline 2.5 & 11.38 & 5.5 & 7 & 100 & 11 \\
\hline 1.84 & 8.2 & 10 & 5 & 100 & 12 \\
\hline 1.97 & 8.82 & 5.5 & 5 & 150 & 13 \\
\hline 2.53 & 11.28 & 10 & 7 & 50 & 14 \\
\hline 2.6 & 11.96 & 10 & 9 & 100 & 15 \\
\hline 2.51 & 11.44 & 5.5 & 7 & 100 & 16 \\
\hline 2.48 & 11.39 & 5.5 & 7 & 100 & 17 \\
\hline
\end{tabular}

Table 2. Analysis of Variance and Regression Coefficients Estimated Cell Dry Weight Production

\begin{tabular}{cccccc} 
Expression & $\begin{array}{c}\text { Sum of } \\
\text { squares }\end{array}$ & Mean square & $\begin{array}{c}\text { Degrees of } \\
\text { freedom }\end{array}$ & F-Value & P-Value \\
\hline Model & 43.01 & 4.78 & 9 & 21.63 & $\mathbf{0 . 0 0 0 3}$ \\
A & 2.74 & 2.74 & 1 & 12.40 & $\mathbf{0 . 0 0 9 7}$ \\
B & 30.65 & 30.65 & 1 & 138.79 & $<0.0001$ \\
C & 1.02 & 1.02 & 1 & 4.63 & $\mathbf{0 . 0 6 8 5}$ \\
AB & 0.46 & 0.46 & 1 & 2.09 & $\mathbf{0 . 1 9 1 2}$ \\
AC & 0.02 & 0.02 & 1 & 0.089 & $\mathbf{0 . 7 7 4 4}$ \\
BC & 0.45 & 0.45 & 1 & 2.03 & $\mathbf{0 . 1 9 7 0}$ \\
A $^{2}$ & 0.84 & 0.84 & 1 & 3.82 & $\mathbf{0 . 0 9 1 6}$ \\
B $^{2}$ & 6.66 & 6.66 & 1 & 30.14 & $\mathbf{0 . 0 0 0 9}$ \\
C $^{2}$ & 0.28 & 0.28 & 1 & 1.26 & $\mathbf{0 . 2 9 8 0}$ \\
residua & 1.55 & 0.22 & 7 & & \\
\hline
\end{tabular}

Table 3. Analysis of variance and regression coefficients estimated CGC weight production

\begin{tabular}{cccccc} 
Expression & $\begin{array}{c}\text { Sum of } \\
\text { squares }\end{array}$ & Mean square & $\begin{array}{c}\text { Degrees of } \\
\text { freedom }\end{array}$ & F-Value & P-Value \\
\hline Model & 2.04 & 0.33 & 9 & 17.92 & $\mathbf{0 . 0 0 0 5}$ \\
A & 0.13 & 0.13 & 1 & 10.31 & $\mathbf{0 . 0 1 4 9}$ \\
B & 1.45 & 1.45 & 1 & 114.51 & $<\mathbf{0 . 0 0 0 1}$ \\
C & 0.068 & 0.068 & 1 & 5.42 & $\mathbf{0 . 0 5 2 7}$ \\
AB & 0.024 & 0.024 & 1 & 1.90 & $\mathbf{0 . 2 1 0 1}$ \\
AC & 2.250 & 2.250 & 1 & 0.018 & $\mathbf{0 . 8 9 7 5}$ \\
BC & 0.034 & 0.034 & 1 & 2.71 & $\mathbf{0 . 1 4 3 6}$ \\
A & 0.051 & 0.051 & 1 & 4.02 & $\mathbf{0 . 0 8 5 0}$ \\
B $^{2}$ & 0.27 & 0.27 & 1 & 21.74 & $\mathbf{0 . 0 0 2 3}$ \\
C $^{2}$ & 0.015 & 0.015 & 1 & 1.21 & $\mathbf{0 . 3 0 7 5}$ \\
\hline residual & 0.088 & 0.22 & 7 & & \\
\hline
\end{tabular}

The software proposed a nonlinear regression model for biomass production and a nonlinear regression model for CGC production based on code variables as follows:
Biomass $=11.40+0.59 \mathrm{~A}+1.96 \mathrm{~B}+0.34 \mathrm{AB}-0.070 \mathrm{AC}$ $-0.33 B C+0.45 A^{2}-1.26 B^{2}-0.26 C \quad$ Equation 3

$C G C=2.51+0.13 A+0.42 B+0.092 C+0.077 A B-$ 7.500E-003 AC - $0.092 B C+0.11 A^{2}-0.26 B^{2}-0.060 C^{2}$ Equation 4 
In Figure 1-A, two-dimensional diagrams (A) the effect of acidity on aeration percentage; $(B)$ the effect of aeration percentage on acidity; (C) Effect of acidity inoculum on cell dry weightand 1-B (3D) Effect of acidity to aeration percentage; (B) Effect of aeration percentage to acidity; (C) Effect of acidity percentage to acidity on cellular dry weight. In Figure 2-A, the twodimensional diagram (A) the effect of acidity on aeration percentage; (B) the effect of aeration percentage on acidity; (C) Effect of inoculum percentage on acidity and 4-B three-dimensional diagrams (A) Effect of acidity on percentage aeration; (B) Effect of percentage of inoculum on acidity; (C) The effect of the percentage of inoculum acidity on CGC weight is given.

The data obtained in this study showed that there is a linear relationship between cell mass production and CGC.

\section{(a)}

A)

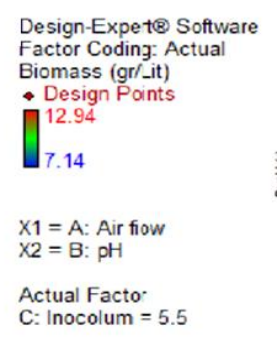

(b)
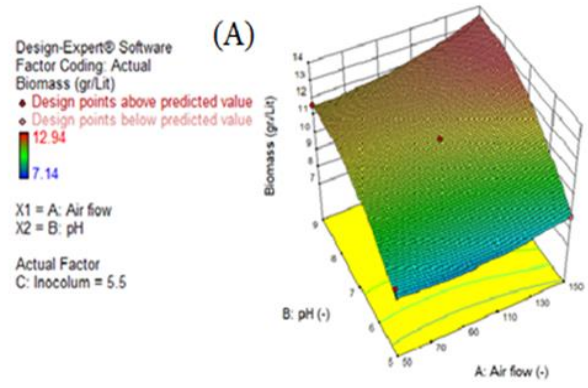

(c)

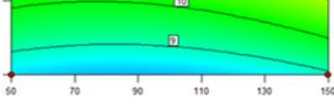

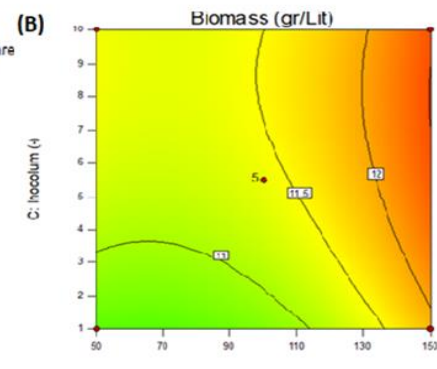

A. Air fow (-)

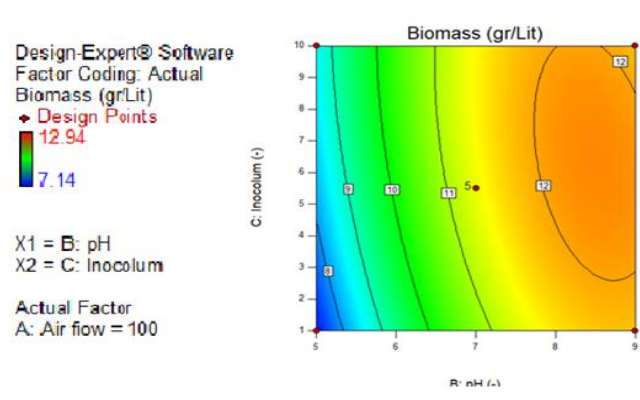

Design-Expene Sofwar Factor Coding: Act Biomass (gr/it) - Design Paint

7.14

$X_{1}=A:$ Air fiow
$X_{2}=C:$ Inocolum

Actual Factor

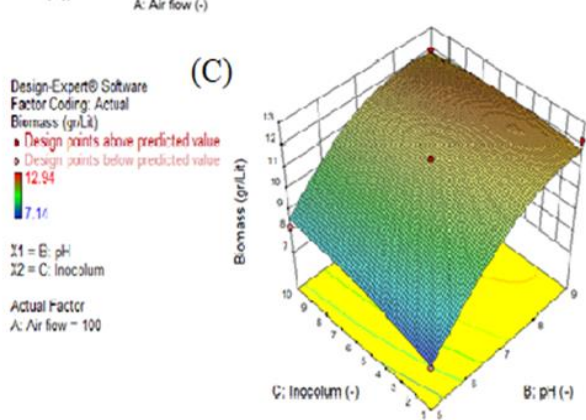

Figure 1. (a) Two-dimensional graph (A) Effect of acidity on aeration percentage; (B) Effect of aeration percentage on acidity; (C) Effect of acidity on aeration percentage; and (B) Three-dimensional graph (A) Effect of acidity on aeration percentage; (b) Effect of aeration percentage on aeration; (C) Effect of acidity percentage on acidity on cell dry weight. 
(a)
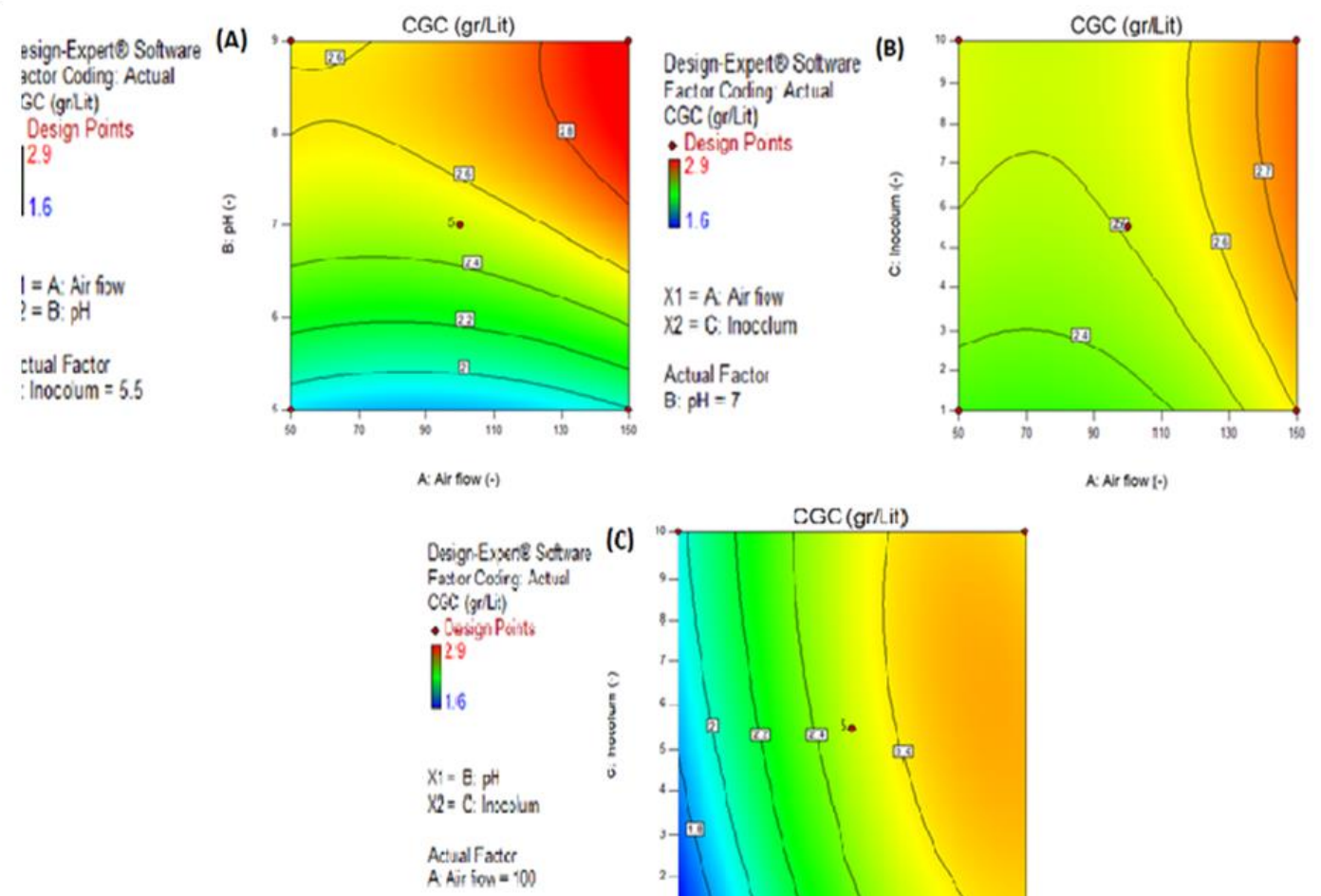

(b)
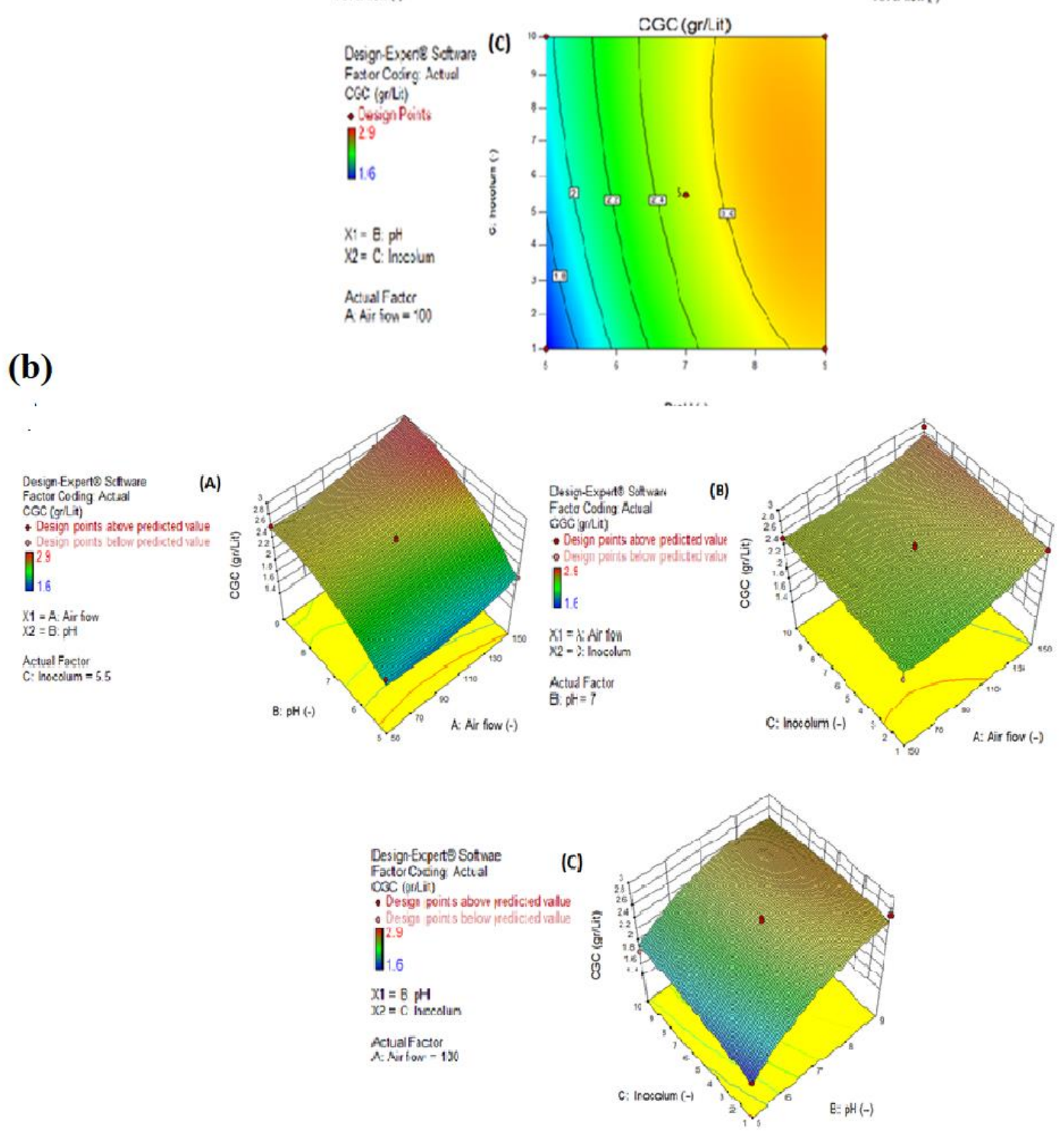

Figure 2. (a) Two-dimensional diagram (A) Effect of acidity on aeration percentage; (B) Effect of aeration percentage on aeration; (C) Effect of inoculum percentage on acidity and (b). Three-dimensional graph (A) of the effect of acidity on aeration percentage; (B) Effect of aeration percentage on aeration; (C) Effect of acidity percentage on acidity on CGC weight. 


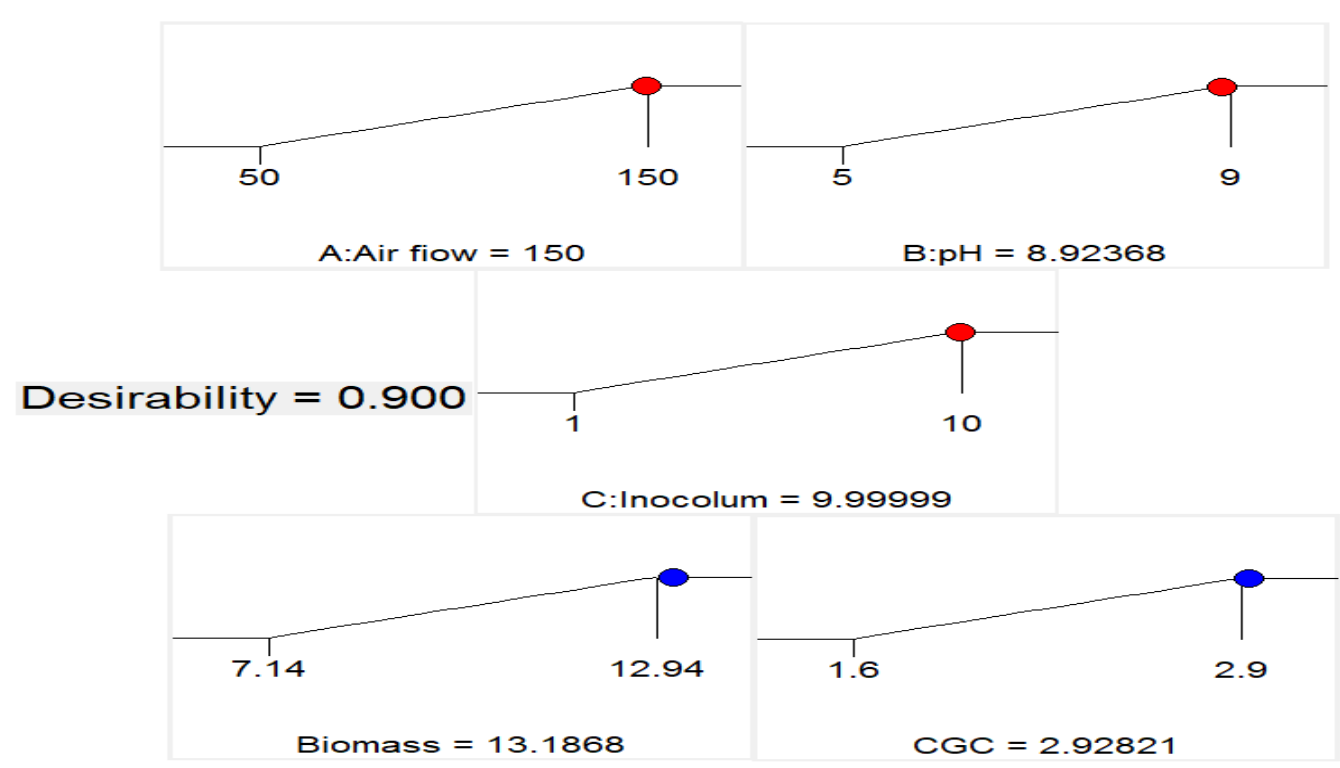

Figure 3. Optimum point to enhance fungal growth and CGC production

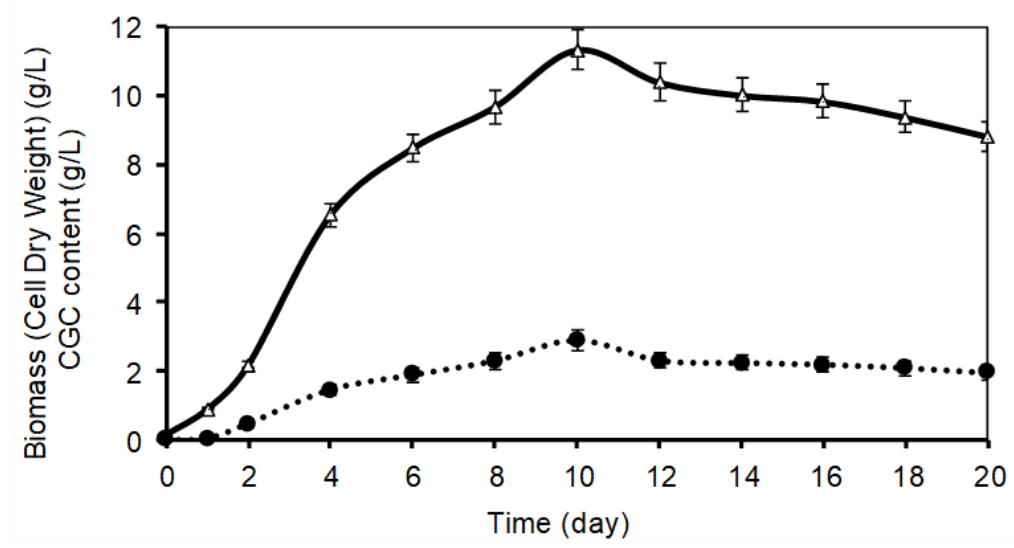

Figure 4. Temporal changes of cellular dry weight growth, production of CGC in PDB medium; Schizophyllum commune, CGC production curve $(\bullet)$, mycelium growth curve $(\Delta)$

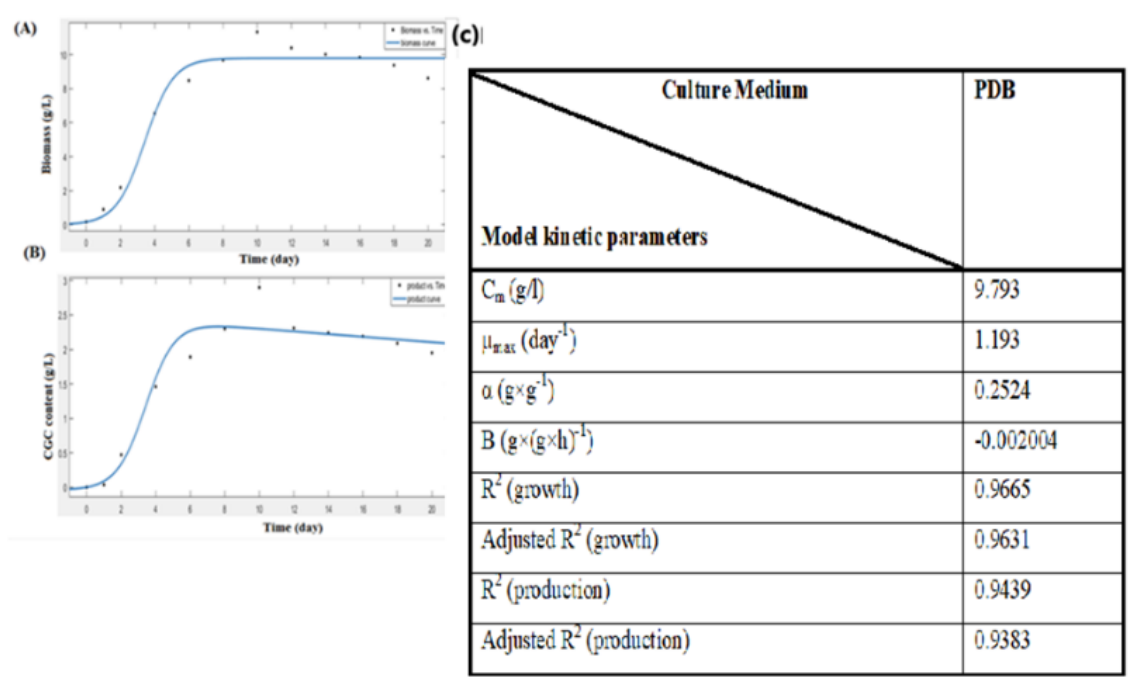

Figure 5. Laboratory data and regression curves of (A) biomass and (B) Figure 5. Laboratory data and regression curve (A) biomass and (B) CGC production in mycelial form of Schizophyllum commune inea fungus fermentation in PDB medium (.) laboratory data and (-) regression curve and (C) Coefficients of mycelial growth and CGC production obtained from the model. 


\section{Discussion}

Based on the Figures 1-5, it can be said that as the aeration progresses and the alkaline $\mathrm{pH}$ increases, the CGC level increases. In 2001, Amorim et al. investigated the preparation of CGC at identical conditions and initial $\mathrm{pH}$ ranging from $5-6.5$ and found that at $\mathrm{pH}=6.5$ the highest amount of CGC was produced (24). According to a 2006 study by Feofilova et al. about changing CGC content and composition during the development of ascites in submerged cultures, they found out that the composition and content of CGC clearly depend on the fungal development stage and the maximum amount of CGC production. Mycelium was observed in acidic medium in liquid culture (7).

It can be said that the present study is consistent with the studies of Amorim and Feofilova in 2001 and 2006, and as the alkaline $\mathrm{pH}$ progresses, CGC production increases $(7,24)$. The important influence of the initial $\mathrm{pH}$ of the environment can be justified by the fact that the $\mathrm{pH}$ of the environment can affect membrane function, cell morphology, nutrient uptake and production of extracellular and intracellular products (25).

Specific growth coefficient of Schizophyllum commune native kumina $(\max \mu)$ is 0.991-day. In 2018, Moraditanha et al. studied the kinetics of growth and production of CGC from gonoderma leucidum in the immersed medium. After investigating the changes; the specific growth coefficient $(\max \mu)$ was found to be 0 5274 day-1 (22). According to the specific growth coefficient obtained, Schizophyllum commune has a faster growth and production of CGC than Gonoderma leucidium.

Also, the kinetic model of growth and production of CGC from S. commune in this study is in line with the model of Tang et al. (2004) on G. leucidium and Feng et al. (2010) study on structural model of polysaccharide production from fungi Shitaka (28).

\section{Conclusion}

Based on the optimization of the optimum conditions, aeration percentage of $150, \mathrm{pH}$ of 8.92 and inoculation percentage of 9.99 were obtained. The kinetic parameters of growth and production have been investigated and matching of experimental data with logistic growth model with R2=0.9665 and Luedeking and Piret $s$ model for production with R2 $=0.9439$ showed good agreement. According to the curve plotted on day 10, it was selected for having the highest cellular dry weight and CGC.

\section{Acknowledgment}

This research is the result of Master's thesis with the code 15830560962037.

\section{Conflict of Interest}

Authors declared no conflict of interests. 


$$
\begin{aligned}
& \text { مجله ميكروبشناسى يزشكى ايران }
\end{aligned}
$$

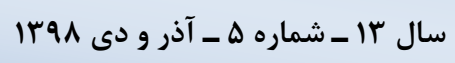

$$
\begin{aligned}
& \text { Journal homepage: www.ijmm.ir }
\end{aligned}
$$

\section{بررسى توليد كميلكس كيتين-كلوكان در كشت غوطه ور قارج دارويى شيزوفيلوم كومينه: بهينه سازى و سينتيك رشد}

محدثه زينعلى'، اشرف السادات حاتميان زارمى “'، محدثه لارى يور'

$$
\begin{aligned}
& \text { '. . كروه علوم زيستى، دانشكده علوم، واحد شمال، دانشكاه آزاد اسلامى، تهران، ايران }
\end{aligned}
$$

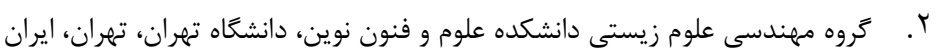

\section{جكيله}

زمينه و اهداف: قارج شيزوفيلوم كومينه از جمله قارجهاى دارويى - غذايى مههم در دنياست كه به دليل دارا بودن تركيبات

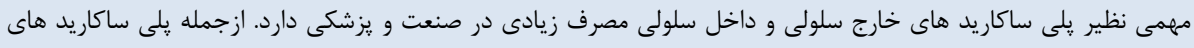

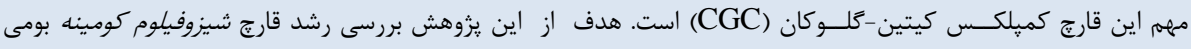

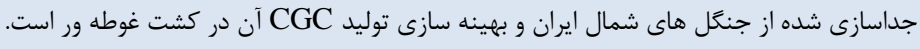

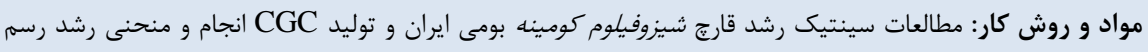

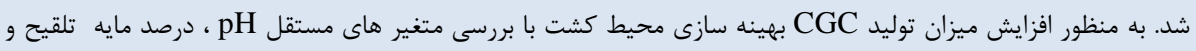
درصد هوادهى با روش سطح ياسخ انجام شد.

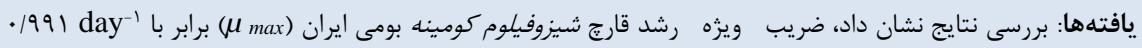

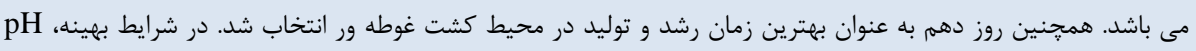

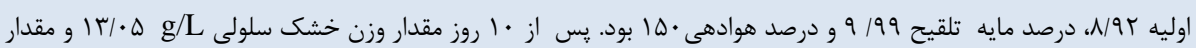
كميلكس كيتين-كلوكان توليدى به ورصد

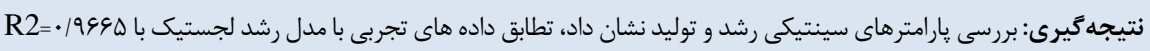

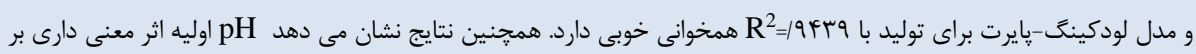
رشد اين قارج دارد.

$$
\text { كليد وازهها: شيزوفيلوم كومينه، كميلكس كيتين-كلوكان، بهينه سازى، كشت غوطه ور }
$$

كجىرايت (C) مجله ميكروب شناسى بزشكى ايران: دسترسى آزاد؛ كيى بردارى، توزيع و نشر براى استفاده غيرتجارى با ذكر منبع آزاد است.
اطلاعات مقاله

تاريختجه مقاله

دريافت:

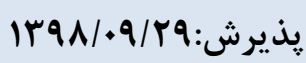

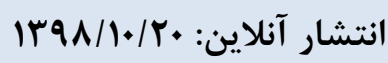

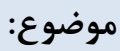

بيوتكنولوزى ميكروبى

نويسندهُ مسئول:

اشرف السادات حاتميان زارمى، كروه مهندسى علوم زيستى دانشكده علوم و فنون

نوين، دانشخاه تهران، تهران، ايران ايميل: hatamian_a@ut.ac.ir
ماده جاذب رطوبت بوده و در محيطهاى آبى و روغنى متورم مىشود (F) و مى F)

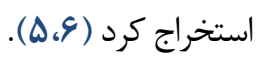

حضور فراوان قارجها در طبيعت، رشد سريع ميسيليوم قارجى، تركيب نشدن CGC قارجى با يروتئين و كم بودن تركيبات كربنات موجود در ميسيليومهاى قارجى باعث كاهش هزينه هاى استخراج

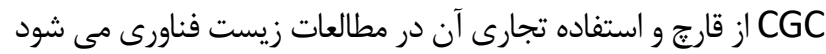
(V). (V) و تراميتيس ورسيكالر از قارجهاى دارويى شناخته شده در جهان مىباشد كه از متابوليتهاى ثانويئ آنها كيتين، كلوكان، كيتوسان،

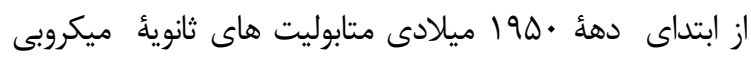

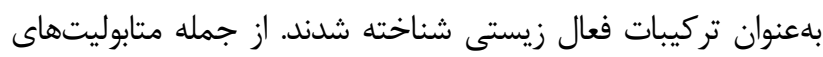
ثانويه مىتوان به كيتين، كيتوسان، شيزوفيلان و كميلكس كيتين-

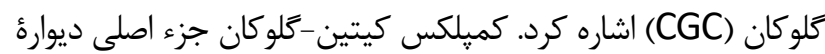
سلولى در مخمرها و قارجها است كه باعث ايجاد ثبات و استحكام سلولها مىشود و كويليمرى از دى كلوكز آمين، ان استيل دى كلوكز آمين و كلوكز است (l) (Y). در كميلكس كيتين-كلوكان نسبت بين كيتين و بتاكلوكان باتوجه به منبع، شرايط محيط كشت و نوع قارت

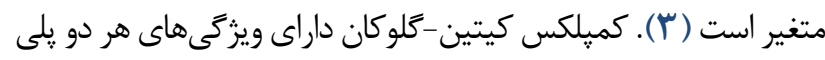
ساكاريد بتا كلوكان و كيتين مىباشد كه در آب نامحلول است ولى يك 
1| • ז، توليد كميلكس كيتين-كلوكان را از قارج دارويى كنودرا

لوسيديوم در محيط كشت هاى مختلف بهينه سازى كردند (Y (Y).

هدف از اين :روهش بررسى متغير هاى اثر گذار در رشد قارج

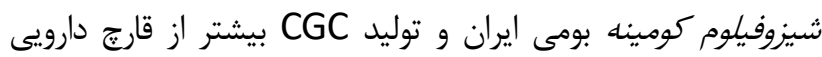

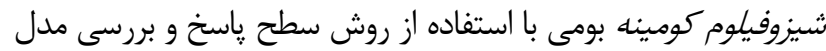
سينتيكى رشد و توليد CGC با استفاده از مدل منطقى و لودكينگ-

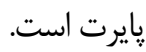

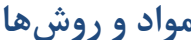

\section{الف) كشت قارج شيزوفيلوم كومينه}

قارج مورد استفاده در اين يزوهش قارجى است كه، بعد از جداسازى از جنكلهاى مازندران و ثبت در NCBI با شماره ثبت مورد مورد استفاده قرار گرفت. سيس در محيط كشت مايع بـ يوتيتو دكستروز براث (PDB) كشت داده شد. مدت • ا روز درشيكر انكوباتور با دماى ل\ درجه سلسيوس و دور •11 دور در دقيقه كرمخانه گذارى شد.

\section{ب) استخراج كميلكس كيتين-گلوكان}

זكرم ميسليوم خشك شده با •9 ميلىليتر از سديم

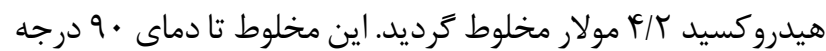
سانتى گراد براى ץ ساعت گرمخانه گذارى شد. مخلوط سانتريفيوز شد و سويرناتانت جدا و دور ريخته شد. سيس رسوب در . ." ميلىليتر آب مقطر استريل شده حل شد و دوباره سانتريفيوز شد.

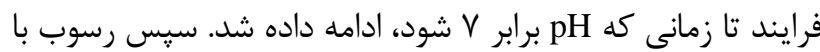

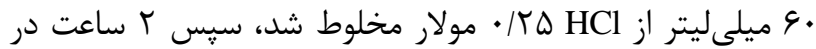

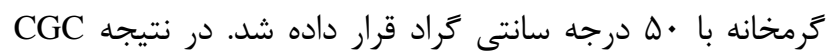
سانتريفيوز شد. رسوب در .ب ميلىليتر آب مقطر حل شد و اين فرايند تا زمانى كه pH سويرناتانت برابر V شود، ادامه داده شد.

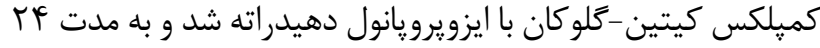

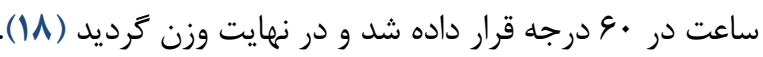

\section{״) طراحى آزمايش و تجزيه و تحليل آمارى}

بلمنظور تخمين اثر متغيرهاى مستقل بر ميزان رشد توده سلولى و توليد يلى

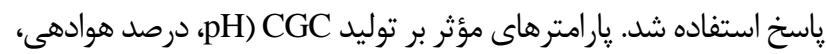
درصد مايه تلقيح اوليه) از قارج شيزوفيلوم كومينه براساس روش BBD از نرمافزار Dox Behnken Design)
شيزوفيلان و كميلكس كيتين-كلوكان هستند كه در موارد گوناگون از آنها استفاده شده است (ه). منشأ صنعتى كميلكس كيتين-كلوكان اسيدسيتريك، از ميسيليوم زائد قارج /سيرزيلوس نايجراست (A). تا كنون CGC از منابع مختلف قارجى مانند آسبرزيلوس نايجر (9)،

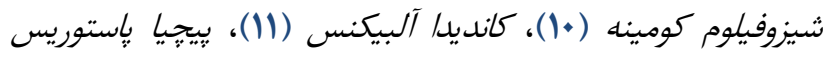

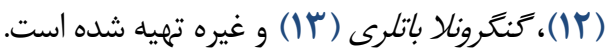

در سالهاى اخير متابوليتهاى مختلفى مانند شيزوفيلان، كيتين، كيتوسان، كميلكس كيتين-كلوكان از قارج شيزوفيلوم كومينه به علت وجود خواص آنتىبادى، ضد انعقاد و فعاليتهاى ضدويروسى تهيه شده و در زمينههاى دارويى، آرايشى و بهداشتى مورد استفاده قرارگرفته است (1، (1). شيزوفيلوم كومينه قارجى رشتهاى و خوراكى متعلق به خانواده بازيديوميستها، راسته آكاريكال و خ خانواده شيزوفيلاسه است كه در سرتاسر جهان بهجز قاره قطب جنوب، در طيف كستردهاى از جنگلهاى حاوى درختان كهنسال قادر به رشد است

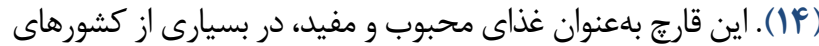
آسيايى و همجنين در شرق و جنوب غربى نيجريه مورداستفاده قرار

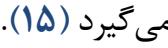

براساس مطالعات Bowman و همكاران در زمينهُ ساختار و سنتز ديواره سلولى قارجى، ديواره سلولى بهطور عمده از كيتين، كلوكان، مانان و كليكويروتئين ها تشكيل شده است كه با يكديكر متصل مىشوند

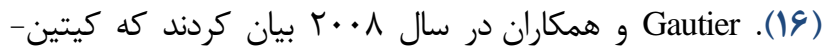
كلوكان، بهعنوان داربست سلولى طبيعى براى مرطوبسازى و و جوانسازى يوست مؤثر است و مطالعات بالينى نشان داد، تركيبات كيتين-كلوكان بىخطر هستند (F). در سال • • • Hao و همكاران بهينهسازى متغيرهاى موثر بر رشد و توليد يلىساكاريد شيزوفيلوم كومينه را بررسى كردند (IV) Smirnou و همكاران در سال II بيان كردند، كشت غوطهور شيزوفيلوم كومينه يك جايگزين قوى براى توليد كميلكس كيتين-كلوكان در مقياس صنعتى است (1) (1). Meichik سلولى قارج هم زيست در گل سنَ يلتى گراى آفت زا شدند (19). Ordoñez با استفاده از آب بحرانى (subcritical water) كيتين و CGC استخراج

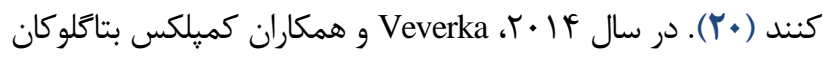
را از منابع مختلفى مانند گياه جو دوسر، جو، جلبك يا خزه دريايى و

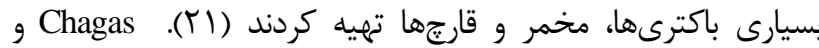

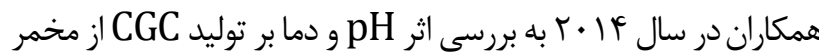

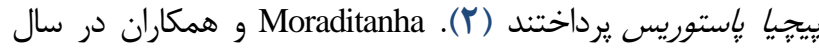


(gx(gxh) مقدارهاى ثابت هستند. اين مدل،

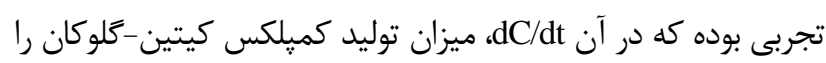
نسبت به سرعت رشد نشان مىدهد و C نشاندهندة توليد كميلكس كيتين-كلوكان بدون توجه به رشد است.

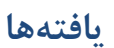

\section{الف) بهينهسازى يارامترهاى موثر بر توليد CGC از قارج}

\section{شيزوفيلوم كومينه بومى ايران}

براى تعيين شرايط بهينه طراحى آزمايش براى سه متغيردرصد

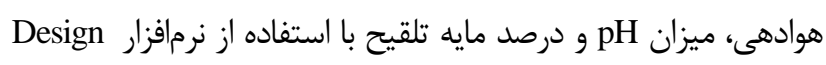

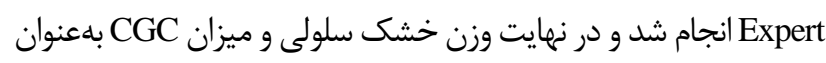

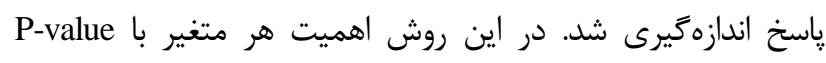

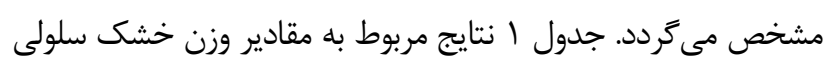

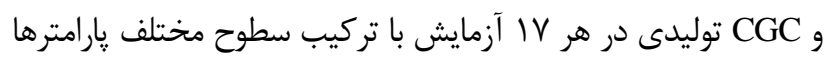

$$
\text { رانشان مى دهد. }
$$

\section{ب) بهينهسازى رشد قارج شيزوفيلوم كومينه و پاسخ}

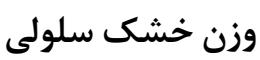

آناليز واريانس نتايج حاصل از آزمايش ها بر حسب ميزان توده

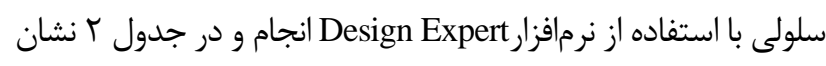

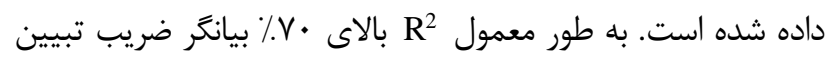

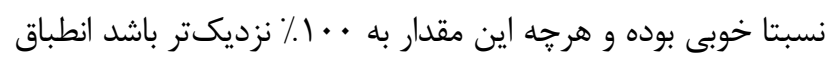

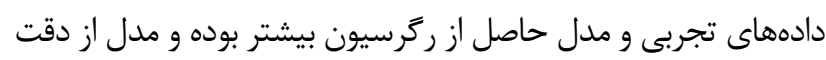

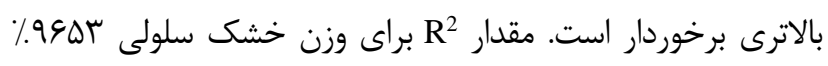

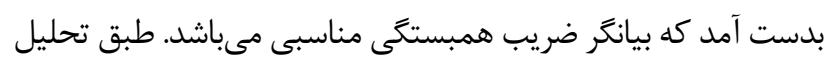

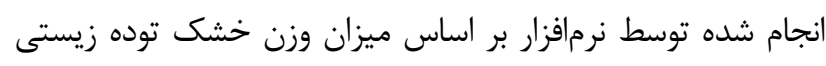

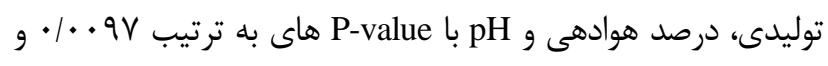

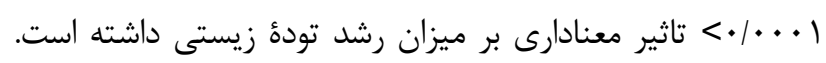
طبق اين تحليل برهمكنشى بين متغيرهاى مورد مطالعه وجود ندارد.

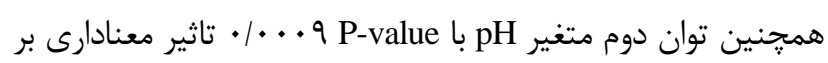

$$
\text { ميزان رشد توده زيستى داشته است. }
$$

معنادار بودن آمارى عبارتها در معادلة ركرسيونى در سطح اطمينان

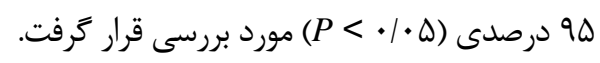

در هر آزمايش محيطهاى كشت با حجم و pH تعيينشده توسط

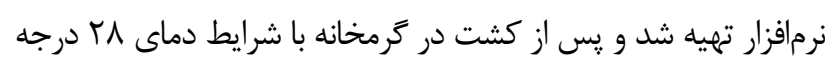

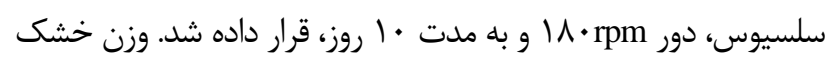

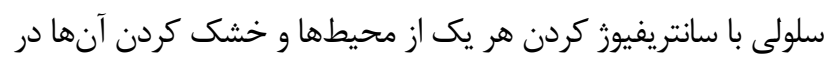

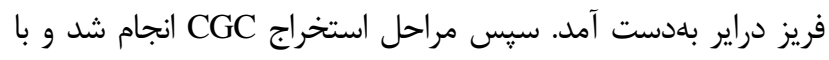
تحليل نتايج حاصله توسط نرمافزار شرايط بهينه تعيين شد. ت) بررسى متغير هاى سينتيكى رشد و توليد CGC براى قارج شيزوفيلوم كومينه

براى به دست آوردن منحنى رشد قارج شيزوفيلوم كومينه، اين

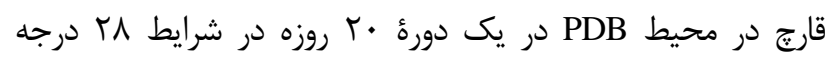

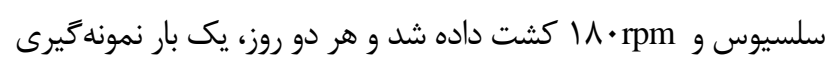

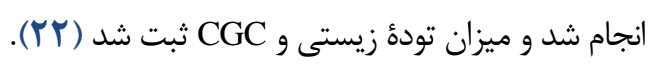
معادله منطقى براى انطباق با منحنى توده زيستى سلولى مورد

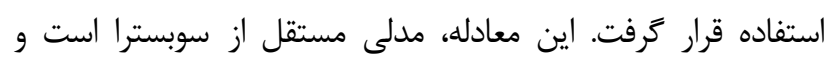

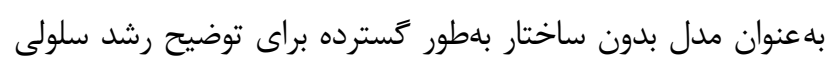

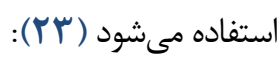

$\mathrm{dC} / \mathrm{dt}=\mu_{\mathrm{m}}\left(1-\mathrm{C} / \mathrm{C}_{\mathrm{m}}\right) \mathrm{C}$

معادله

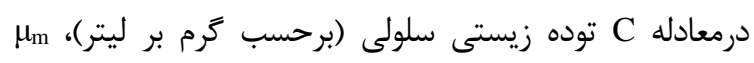

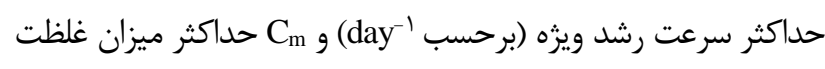
تودة زيستى سلولى به دست آوردنى ( بر حسب كرم بر بر ليتر ) است. مدل

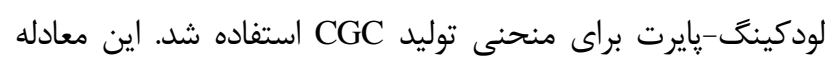
بلمطور كسترده براى بيش بينى متابوليتهاي مناس استفاده مى شود. $(\mathrm{dP}) / \mathrm{dt}=\alpha(\mathrm{dC}) / \mathrm{dt}+\beta \mathrm{C}$

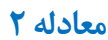

در اينجا p غلظت كميلكس كيتين-كلوكان ( بر حسب كرم بر

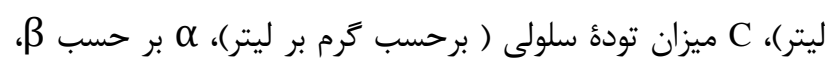

\begin{tabular}{|c|c|c|c|c|c|}
\hline \multicolumn{2}{|c|}{ لراسخها } & \multicolumn{3}{|c|}{ هار امتر ها } & \multirow[t]{2}{*}{ شمارة آزمايش } \\
\hline ميزان(G/L) (CGC) & ميزان ميسيليوم(g/L) & (C ) درصد مايه تلقيح (C) & (B) $\mathrm{pH}$ & A: در صد هوادهى & \\
\hline$r / \Delta$ & (1/R & $\Delta / \Delta$ & v & 1. & 1 \\
\hline$r / 9$ & $1 K / 9 F$ & 1. & v & 10 . & r \\
\hline r/9 & $\mid K / \cdot F$ & 1 & v & 10 . & r \\
\hline$r / \Lambda \Lambda$ & $1 r / 9$ & $\Delta / \Delta$ & 9 & 10 . & r \\
\hline
\end{tabular}

جدول ا. طراحى آزمايش باكس بنكن (BBD) و نتايج به دست آمده براساس وزن خشك سلولى و ميزان CGC 


\begin{tabular}{|c|c|c|c|c|c|}
\hline \multicolumn{2}{|c|}{ باسخها } & \multicolumn{3}{|c|}{ هار امتر ها } & \multirow{2}{*}{ شمارة آزمايش } \\
\hline$r / \Delta \Delta$ & $11 / 48$ & $\Delta / \Delta$ & $v$ & $1 \ldots$ & \\
\hline$T / N Y$ & IT/KF & 1 & 9 & $1 \ldots$ & 4 \\
\hline $1 / 9$ & V/lF & 1 & $\Delta$ & $1 \ldots$ & v \\
\hline r & N/9G & $\Delta / \Delta$ & $\Delta$ & $\Delta$. & 1 \\
\hline$r / 9$ & $11 / 9 \Lambda$ & $\Delta / \Delta$ & 9 & $\Delta \cdot$ & 9 \\
\hline$r / T$ & $1 \cdot 11$ & 1 & v & $\Delta \cdot$ & 1. \\
\hline$r / \Delta$ & $\| / r \Lambda$ & $\Delta / \Delta$ & $v$ & $1 \ldots$ & 11 \\
\hline $1 / A F$ & $N / T$ & 1. & $\Delta$ & $1 \ldots$ & IT \\
\hline $1 / 9 V$ & N/Ar & $\Delta / \Delta$ & $\Delta$ & 10. & Ir \\
\hline$r / Q T$ & $11 / r \wedge$ & 1. & v & $\Delta \cdot$ & if \\
\hline$r / 9$ & $11 / 98$ & 1. & 9 & $1 \ldots$ & 10 \\
\hline$r / \Delta \mid$ & WIFF & $\Delta / \Delta$ & v & $1 \ldots$ & 19 \\
\hline$r / F \Lambda$ & $11 / \% q$ & $\Delta / \Delta$ & v & $1 \ldots$ & IV \\
\hline
\end{tabular}

جدول .r. آناليز واريانس و ضرايب ركرسيون تخمين زده شده ميزان توليد وزن خشك سلولى

\begin{tabular}{|c|c|c|c|c|c|}
\hline P-Value & F-Value & درجه آزادى & مربع ميانگين & مجموع مربعات & عبارت \\
\hline س.+. & rI/G & 9 & F/VA & Fr/. & 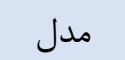 \\
\hline $.1 .+9 V$ & $\mid r / 4$ & 1 & r/VY & $r / V F$ & A \\
\hline$<+|\bullet++|$ & IrN/Vq & 1 & $r \cdot 190$ & $r \cdot 190$ & B \\
\hline $.1 .9 \wedge \Delta$ & F/gr & 1 & $1 / \cdot r$ & $1 / \cdot r$ & $\mathrm{C}$ \\
\hline.$/ 1914$ & $r / \cdot q$ & 1 & $\cdot / 49$ & 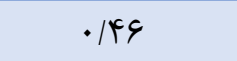 & $\mathrm{AB}$ \\
\hline IVVFF & $\cdot 1 \cdot 19$ & 1 & $\cdot / \cdot r \cdot$ & $\cdot / \cdot r$. & $\mathrm{AC}$ \\
\hline $.119 \mathrm{~V}$ & $r / \cdot r$ & 1 & $\cdot / 19$ & $\cdot / 1 \Delta$ & $\mathrm{BC}$ \\
\hline .1 .919 & r/Ar & 1 & $\cdot \mid \lambda F$ & $\cdot|A| F$ & $\mathrm{~A}^{2}$ \\
\hline $.1+.+9$ & $r \cdot / 1 f$ & 1 & 9199 & 9199 & $\mathrm{~B}^{2}$ \\
\hline \multirow[t]{2}{*}{./rq৯. } & $1 / T 9$ & 1 & $\cdot / T \wedge$ & $\cdot / T \wedge$ & $\mathrm{C}^{2}$ \\
\hline & & V & . & $1 / \Delta \Delta$ & باقيمانده \\
\hline
\end{tabular}

درصد مايه تلقيح به هوادهى؛ (C) اثر درصد مايه تلقيح به اسيديته در ميزان وزن خشك سلولى نشان داده شده است.

ب) بهينه سازى بر اساس پاسخ توليد RGC

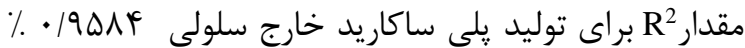

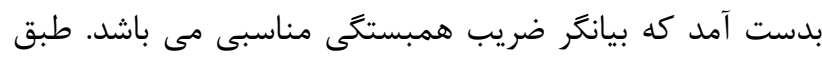

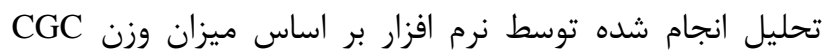
توليدى، درصد هوادهى و اسيديته با P-Value

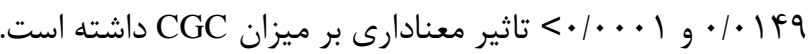
طبق اين تحليل برهمكنش بين متغير هاى مورد مطالعه معنادار
نرمافزار يك مدل ركرسيون غير خطى براى توليد زيست

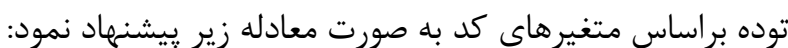
$=11.40+0.59 \mathrm{~A}+1.96 \mathrm{~B}+0.34 \mathrm{AB}-0.070 \mathrm{AC}-$ $\mathrm{CDW}^{*}+0.33 \mathrm{BC}+0.45 \mathrm{~A}^{2}-1.26 \mathrm{~B}^{2}-0.26 \mathrm{C}^{2}$

$$
\text { معادله ميزان وزن خشك سلولى }
$$

در شكل ا-الف نمودارهاى دو بعدى (A) اثر اسيديته به

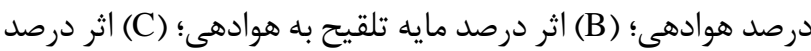

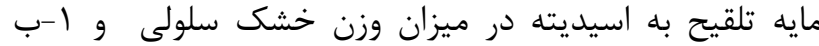

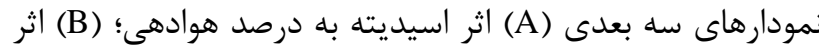




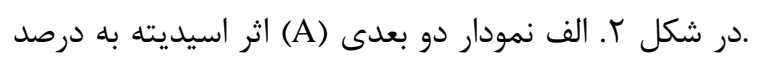
هوادهى؛ (B) اثر درصد مايه تلقيح به هوادهى؛ (C) اثر درصد مايه

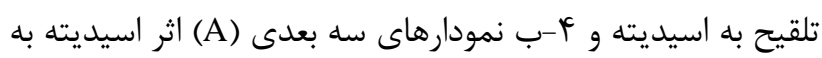

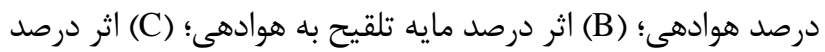
مايه تلقيح به اسيديته در ميزان وزن CGC آورده شده است.

نيست. توان دوم متغير pH با P-value، سץ + • • تاثير معنادارى

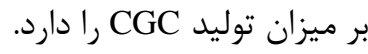
نرمافزار يك مدل ركرسيون غير خطى براى توليد زيست توده براساس متغيرهاى كد به صورت معادله زير ييشنهاد نمود: (CDW) CGC ميزان $2.51+0.13$ A +0.42 B + 0.092 C $+0.077 \mathrm{AB}-7.500 \mathrm{E}-003 \mathrm{AC}-0.092 \mathrm{BC}+0.11 \mathrm{~A}^{2}-0.26$ $B^{2}-0.060 C^{2}$

معادله F

(الف)

A) Design-Expe 18 Software
Factor Codinz Actual
Biomass (gr/-it)
- Design Pants
$\prod_{7.14}^{12.94}$ $X_{1}=A$ : Air fow $X_{2}=B: p H$ Actual FactoC: Inocolum $=5.5$
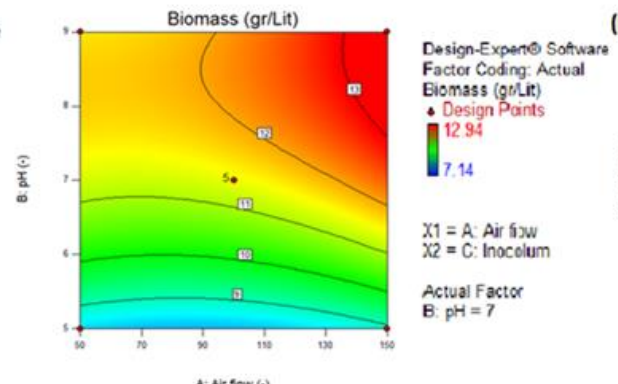

$X_{1}=A \cdot$ Air fix
$X_{2}=C$ : lnoclum Actual Factor
B: $\mathrm{pH}=7$

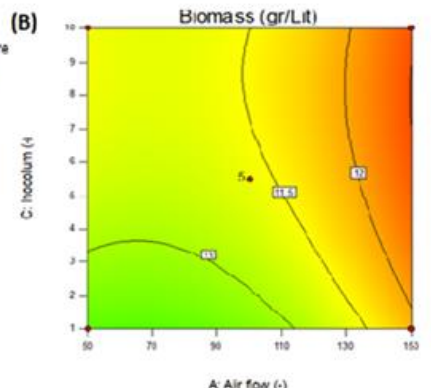

(C)

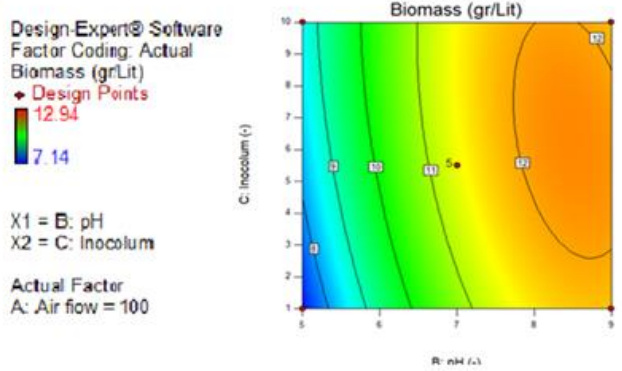

(ب)
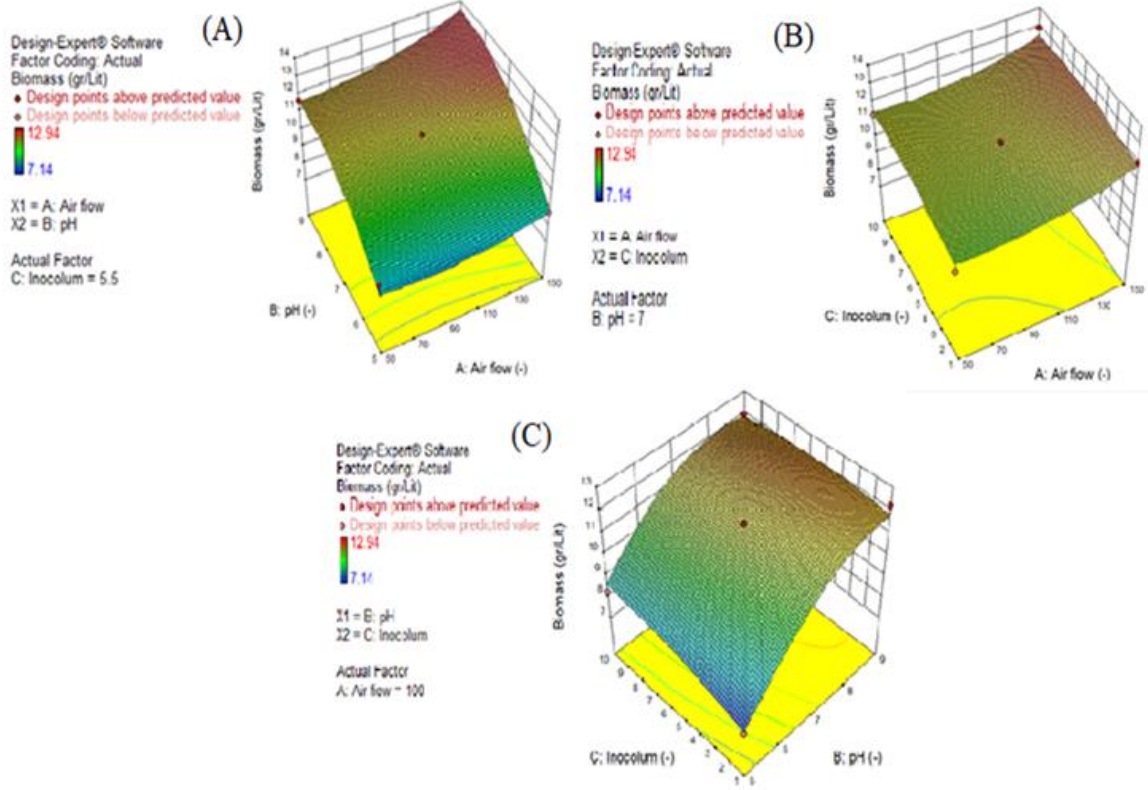

شكل ا. (الف) نمودار دو بعدى(A) اثر اسيديته به درصد هوادهى؛ (B) اثر درصد مايه تلقيح به هوادهى؛ (C) اثر درصد مايه تلقيح به اسيديته و (ب) نمودار

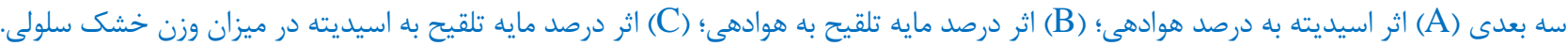




\section{(الف)}

esign-Experte Sotware 3ctor Coding. Actual GC (grlat)

Design Points

$\left.\right|_{1.6} ^{2.9}$

$I=A \cdot$ Air 6 sw $?=\mathrm{B} \cdot \mathrm{pH}$

ttual Factor : Inocoum $=5.5$

(A)

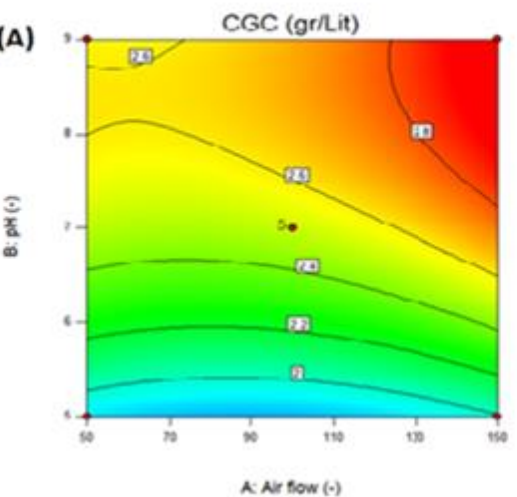

A. NH How (-)

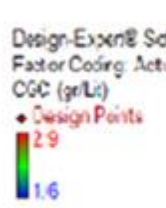

$X_{i}=\mathrm{E} \cdot \mathrm{ph}$ $X_{2}=C$ insciun Actaal Fater A Air fon $=* 00$
Design-Expeto Sotware Factor Coding Actual CGC (gr/lit)

- Desion Ponts

2.9

$X_{1}=A \cdot$ Arr fow $x_{2}=\mathrm{C} \cdot$ Inocclurn

Actual Factor B: $\mathrm{pH}=7$
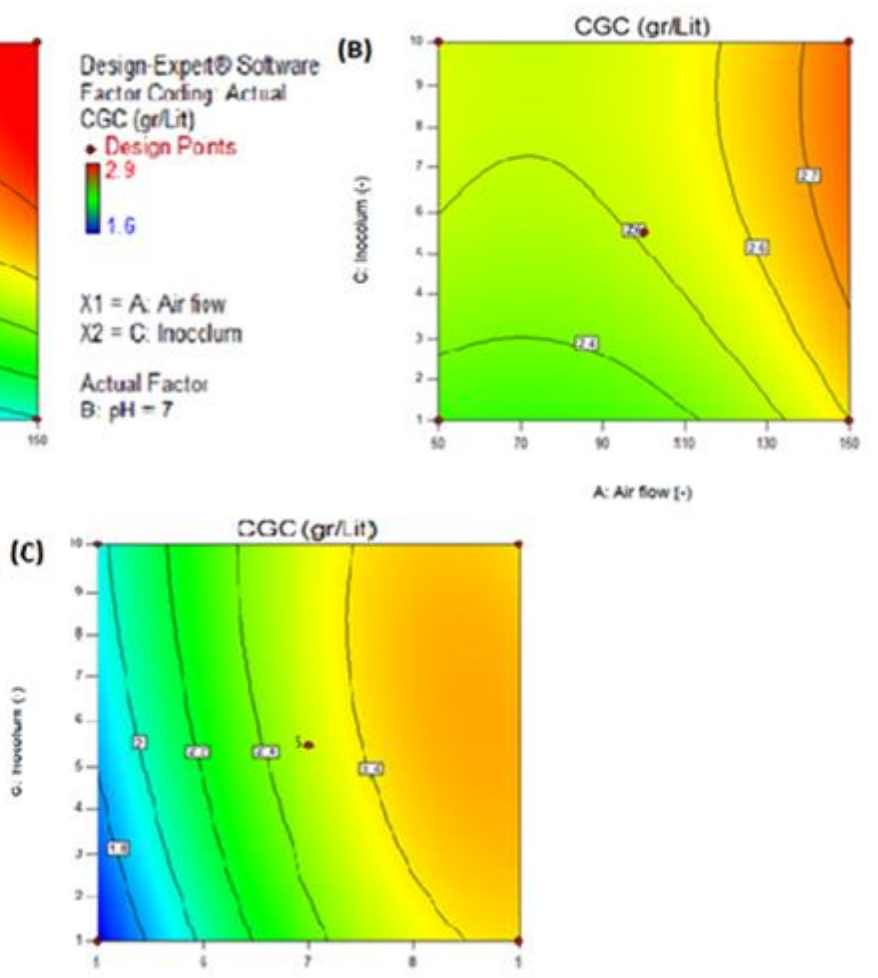

\section{(ب)}
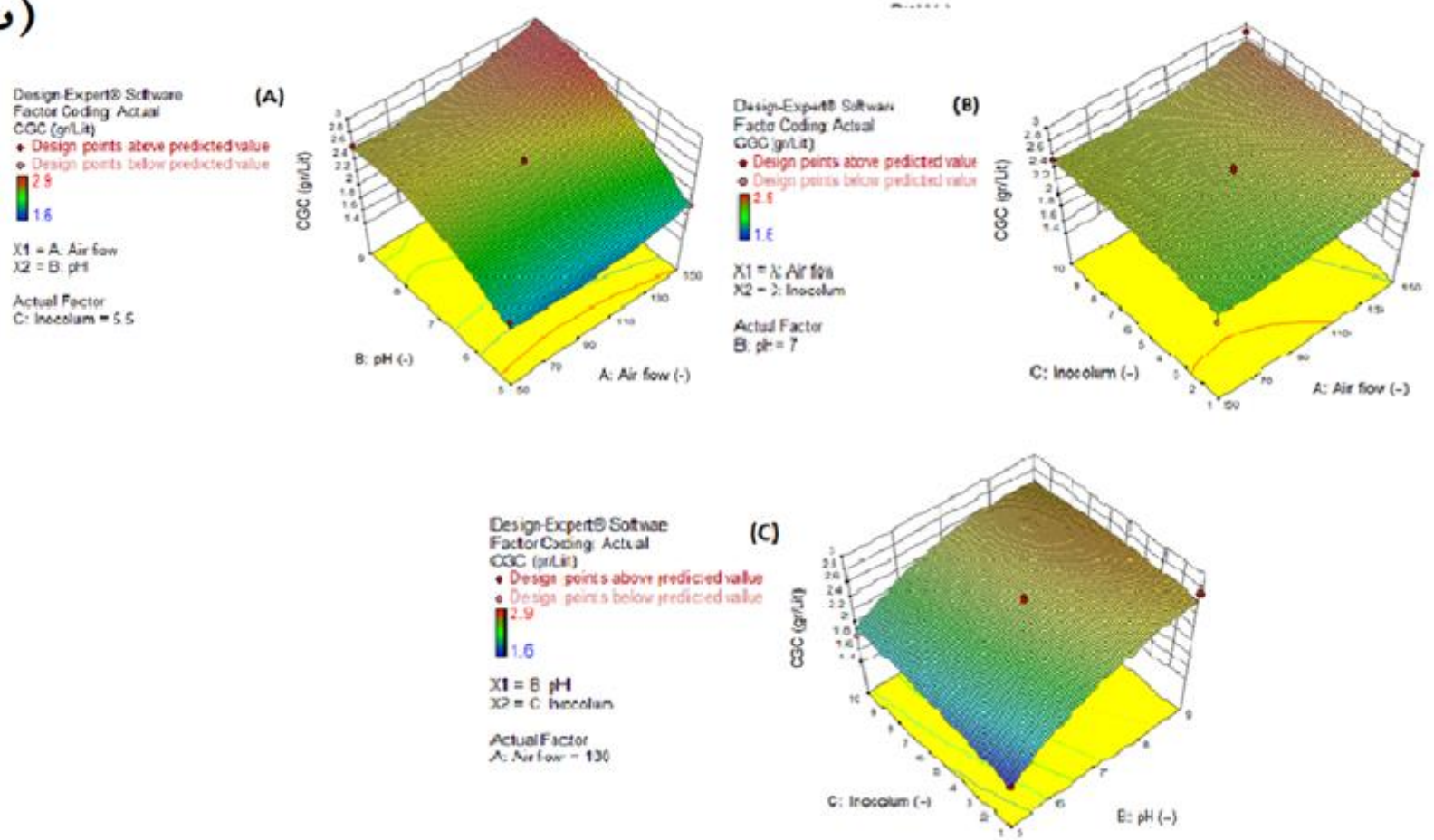

شكل r. (الف) نمودار دو بعدى(A) اثر اسيديته به درصد هوادهى؛ (B) اثر درصد مايه تلقيح به هوادهى؛ (C) اثر درصد مايه تلقيح به اسيديته و (ب). نمودار

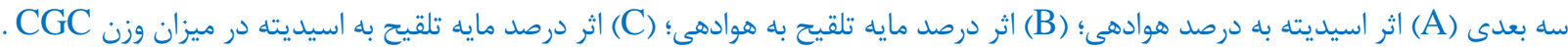


جدول س. آناليز واريانس و ضرايب ركرسيون تخمين زده شده ميزان توليد وزن CGC

\begin{tabular}{|c|c|c|c|c|c|}
\hline P-Value & F-Value & درجه آزادى & مربع ميانَين & مجموع مربعات & عبارت \\
\hline$\cdot / \cdots \Delta$ & IV/9T & 9 & rא/. & $r / \cdot F$ & مدل \\
\hline $.1 .18 q$ & $1 \cdot / \mu 1$ & 1 & س & r/11 & A \\
\hline$<+|+\cdots+|$ & ||$F / \Delta \mid$ & 1 & $1 / 4 \Delta$ & $1 / F \Delta$ & B \\
\hline.$/ . \Delta r V$ & $\Delta / F T$ & 1 & .1 .91 & .1 .91 & $\mathrm{C}$ \\
\hline$\cdot|r| \cdot 1$ & $1 / 9$. & 1 &.$/ \cdot r F$ &.$/ \cdot T F$ & $\mathrm{AB}$ \\
\hline ./^१४ & $\cdot / \cdot 11$ & 1 & $T / T \Delta$. & $r / T \Delta$. & $\mathrm{AC}$ \\
\hline . IfFE & $r / V I$ & 1 & $\cdot / \cdot r F$ & $\cdot / \cdot r f$ & $\mathrm{BC}$ \\
\hline$\cdot 1+\wedge \Delta$ & $r / \cdot r$ & 1 & $\cdot|\cdot \Delta|$ & $\cdot|\cdot \Delta|$ & $\mathrm{A}^{2}$ \\
\hline תr../. & $r I / V F$ & 1 & $\cdot / T V$ & $\cdot / r V$ & $\mathrm{~B}^{2}$ \\
\hline \multirow[t]{2}{*}{$\cdot / \mu \cdot V \Delta$} & $1 / \pi 1$ & 1 & $.1 \cdot 10$ & $.1 \cdot 10$ & $C^{2}$ \\
\hline & & v & . & $\cdot / \cdot \wedge \Lambda$ & باقيمانده \\
\hline
\end{tabular}

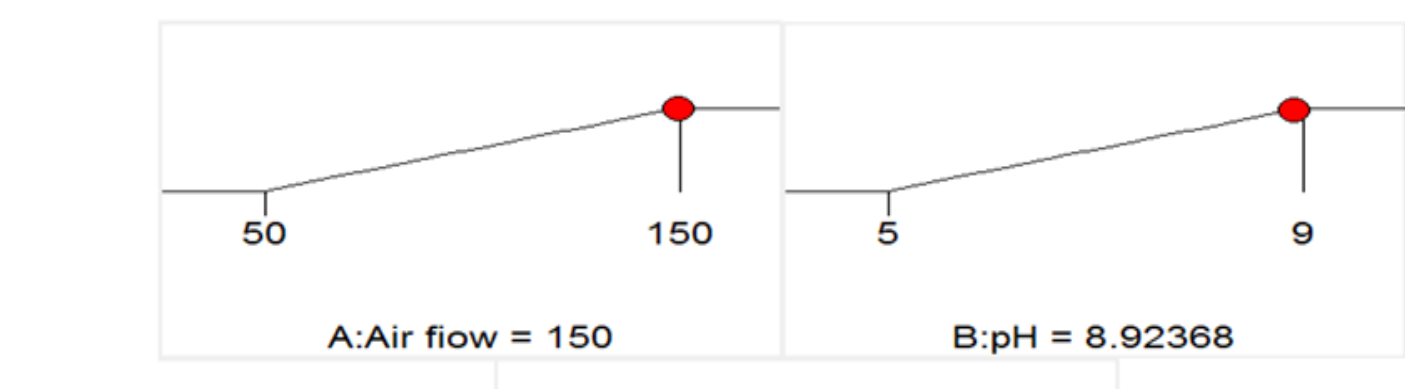

Desirability $=0.900$
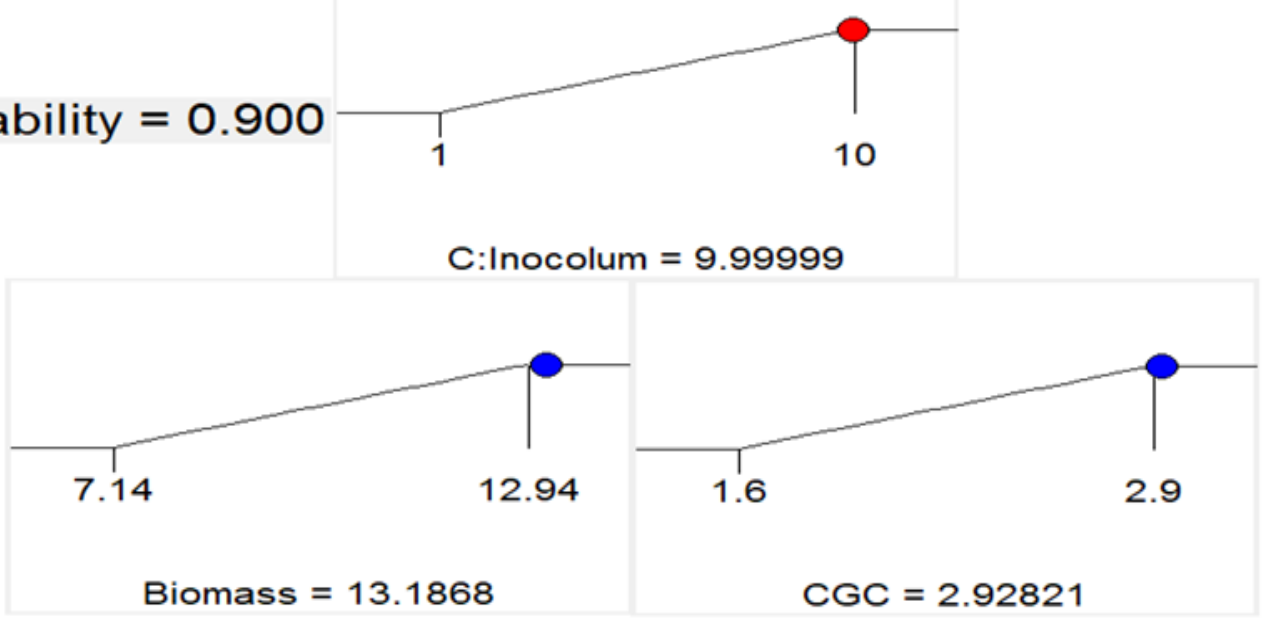

شكل r. تعيين نقطه بهينه به منظور افزايش رشد قارج و توليد CGC 


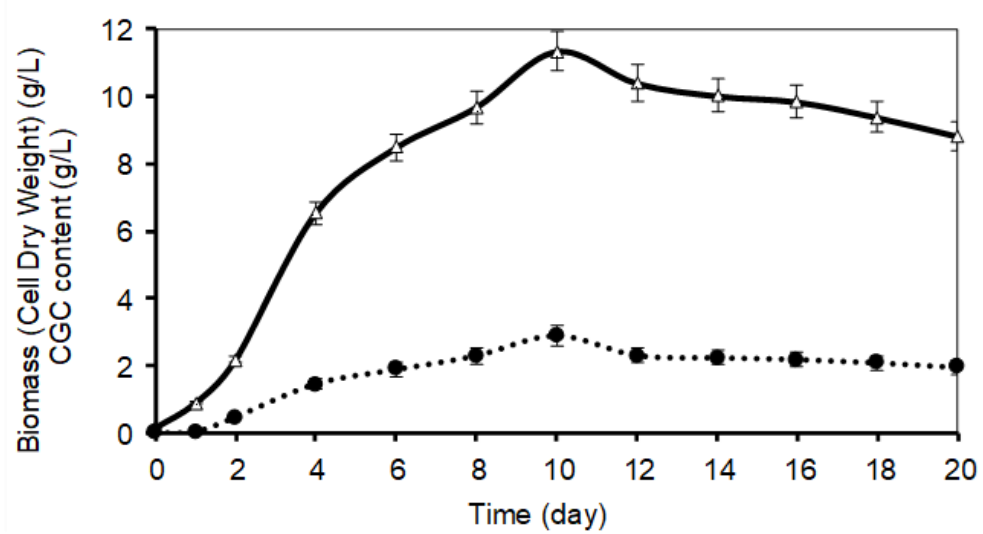

شكل F. تغييرات زمانى رشد وزن خشك سلولى، توليد كميلكس كيتين- كلوكان در محيط كشت PDB قارج شيزوفيلوم كومينه، منحنى توليد

(•)CGC

\begin{tabular}{|c|c|}
\hline هارامترهاى سينتيكى مدل كشل & PDB \\
\hline $\mathrm{C}_{\mathrm{m}}(\mathrm{g} / \mathrm{L})$ & १/V१ \\
\hline$\mu_{\mathrm{m}}\left(\right.$ day $\left.^{-1}\right)$ & $1 / 194$ \\
\hline$\alpha\left(g \times g^{-1}\right)$ & - /TAYY \\
\hline$\beta\left(g \times(g \times h)^{-1}\right)$ & $-\cdot / \cdot r \cdot r$ \\
\hline (رشد) &.$/ 949 \Delta$ \\
\hline (رشد)Adjusted-R² & | \\
\hline R R R R & . $1944 q$ \\
\hline Adjusted-R22 (توليد) & . \\
\hline
\end{tabular}

(A)
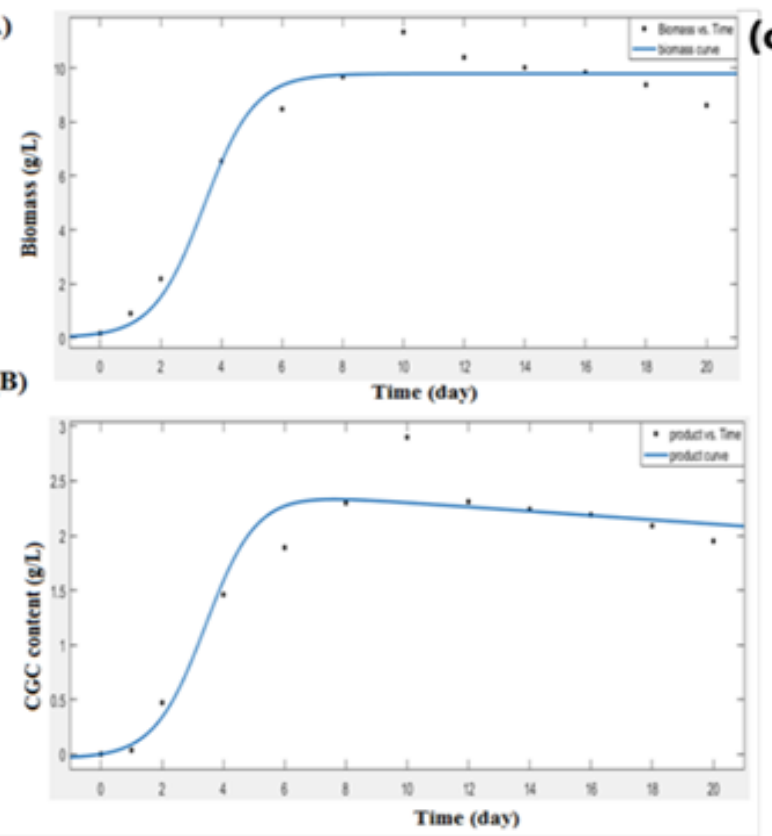

شكل ه. دادهاى آزمايشكاهى و منحنى ركرسيون (A) توهه زيستى و (B) توليد كميلكس كيتين-كلوكان در شكل ميسيليومى تخمير قارج شيزوفيليوم كومينه

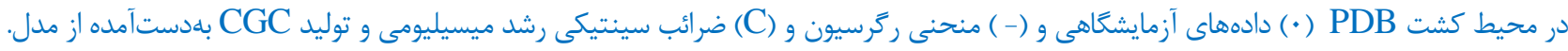

واقع براساس نرمافزار در اسيديته N/9T، درصد مايه تلقيح 9/99 و و

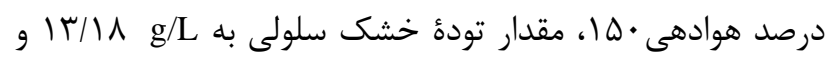

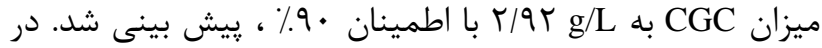

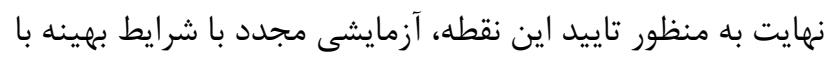

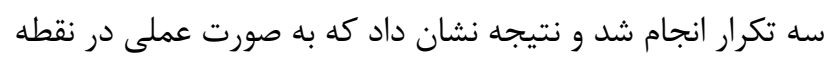

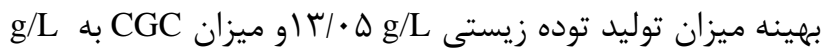

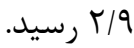

با توجه به نمودارهاى فوق مىتوان كفت كه هرجه به سمت

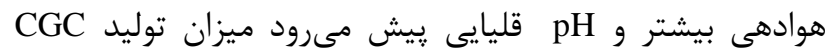
افزايش مى يابد.

ت) تعيين نقطه بهينه و بررسى ميزان وزن خشك سلولى و CGC

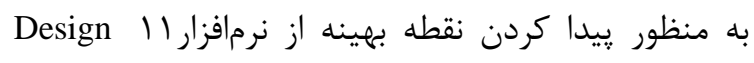

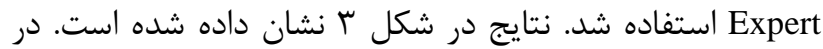


بوده، كه به اين معنى است كه رابطه خطى بين توده سلولى و

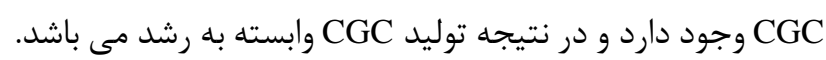

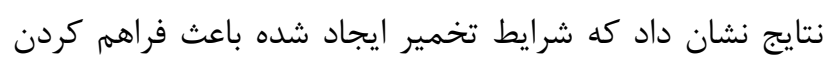

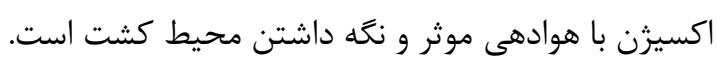
دادههاى بلمدستآمده در اين يروهش نشان داد كه بين توليد توده سلولى و CGC رابطة خطى وجود دارد. مدل سينتيكى ارائه

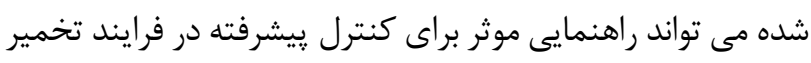
براى توليد صنعتى متابوليت از قارج دارويى شيزوفيلوم كومينه باشد.

\section{بحث}

با توجه به نمودارهاى فوق مى توان كَت كه هر جه به سمت

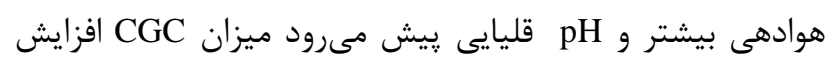

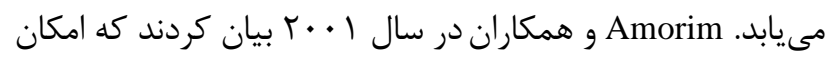

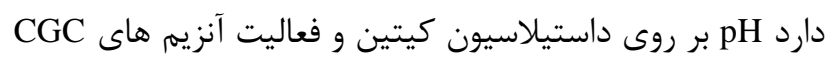

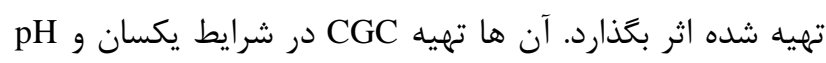

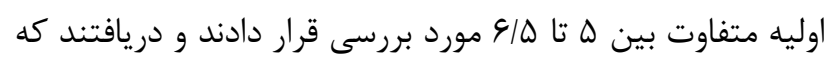

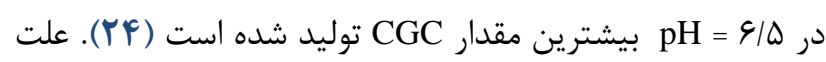

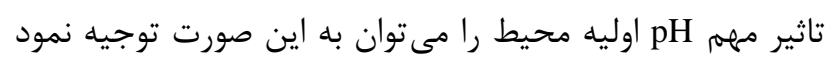

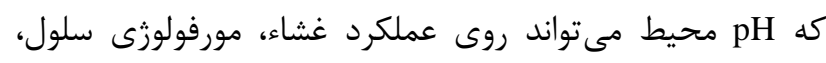

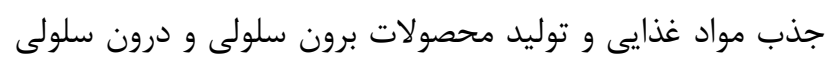
تأثير كذار باشد (r山) (r山).

طبق مطالعاتى كه در سال 9. Feofilova T و همكاران در

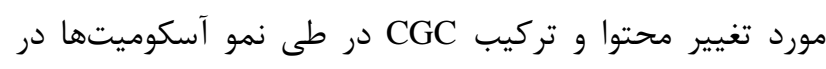

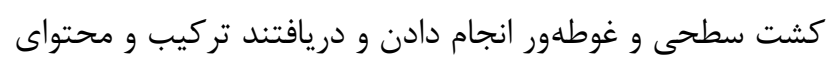

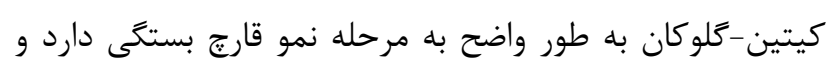

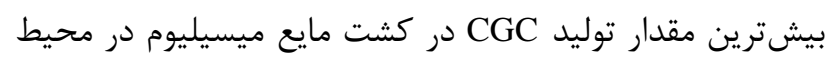

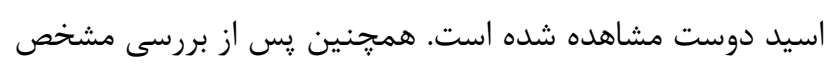

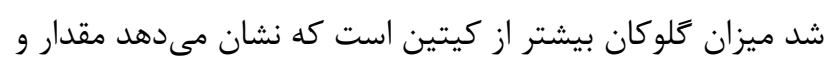

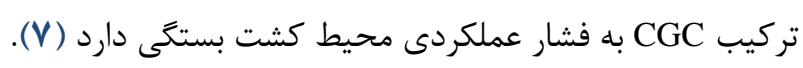
در سال ها • Farinha و همكاران توليد كميلكس كيتين-

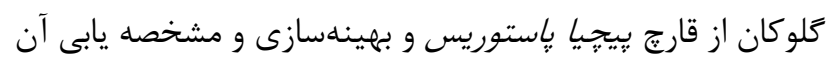

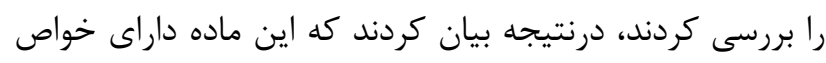

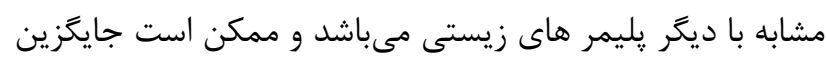

$$
\text { خوبى براى محصولات دارويى باشد (ع). }
$$

Abdel-Gawad و همكاران در سال 19 • ب توليد كيتوسان

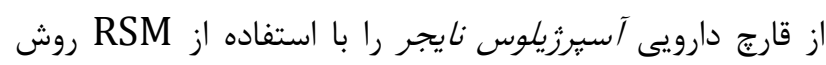

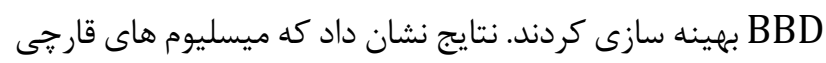

\section{ث) بر رسى منحنى رشد و متغير هاى سينتيكى رشد} و توليد CGC براى قارج شيزوفيلوم كومينه

رس از كشت قارج شيزوفيلوم كومينه در بازه زمانى بيست

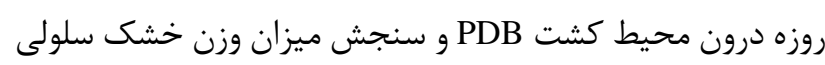

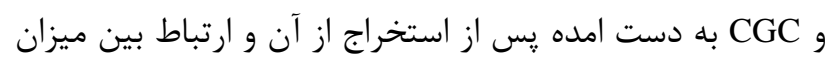

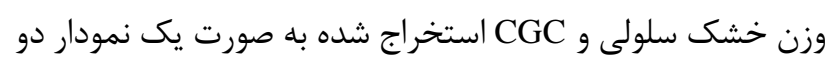
عاملى ترسيم شد.

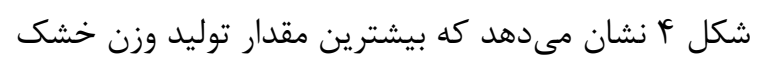

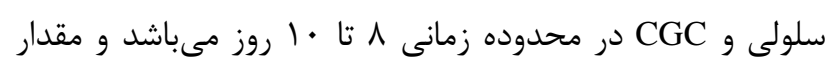
من CGC

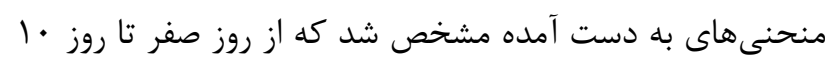

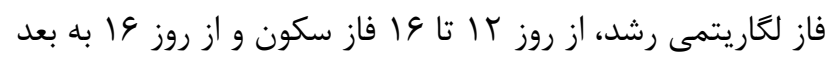

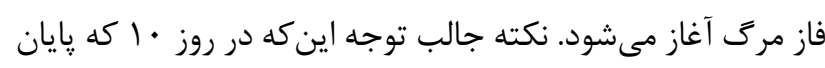

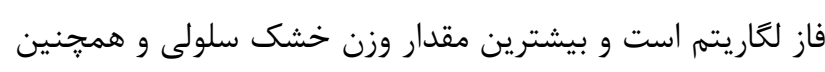

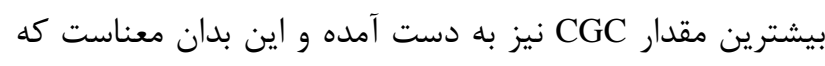

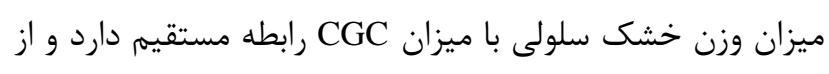

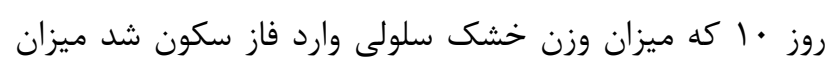
CGC

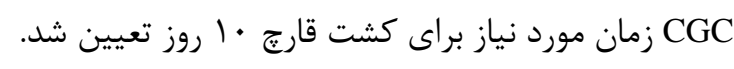
قارجها شكلهاى مختلفى مثل رشتههاى ميسليومى

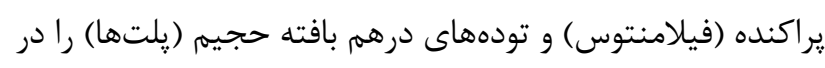

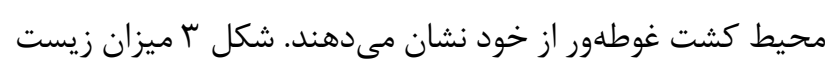
توده سلولى و توليد CGC را در طول تخمير با استفاده از تطابق

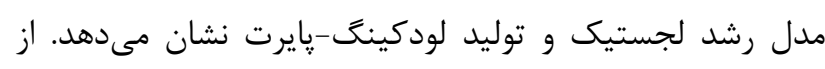

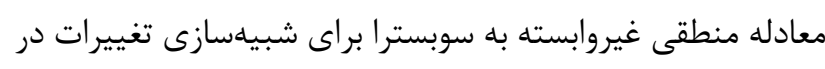

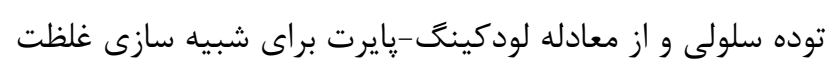

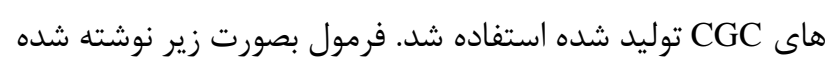

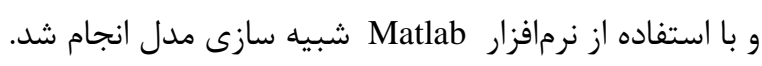
$C(t)=C_{m} /\left(1+\left(\left(C_{m} / C_{0}\right)-1\right) e^{-\mu_{m}}\right)$

معادله هـ

$\mathrm{P}(\mathrm{t})=\mathrm{P} 0+\alpha[\mathrm{C}(\mathrm{t})-\mathrm{C} 0]+\beta \mathrm{Cm}\{\ln ] \mathrm{C} 0 / \mathrm{C}(\mathrm{t})]+\mu \mathrm{m} . \mathrm{t}\} / \mu \mathrm{m}$ معادله مقدارهاى ركرسيون در شكل شماره هـ آمده است. مشخصات

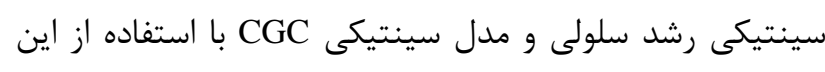

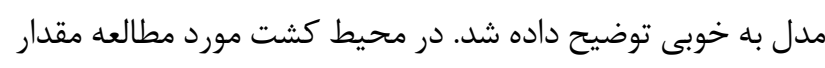

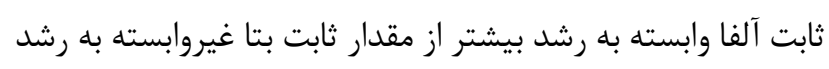


يافته است. فاز سكون بعد از 9 روز ظاهر شده، و بنابراين اين مدل دمد درد

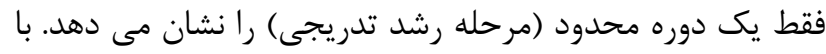

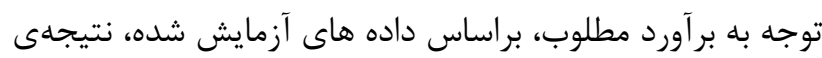

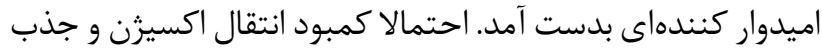

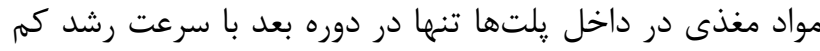

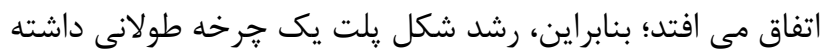
است. مطابق شكل ه ضريب منفى م نشان داد كه توليد وابسته به رشد، برخلاف توليد غيروابسته به رشد افزايش مىيابد. مدل

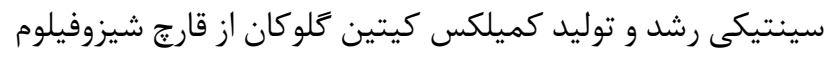
كومينه در اين يزوهش با مدل بررسى شده در مطالعه Tang و

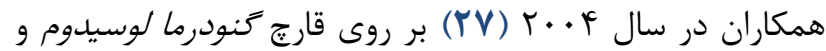

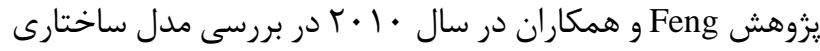
توليد يلى ساكاريد از قارج شيتاكه (Y^) مطابقت دارد.

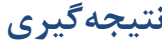

بر اساس بهينهسازى انجام شده شرايط بهينه، درصد هوادهى

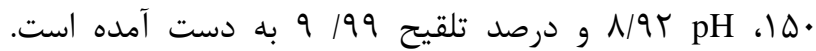
يارامترهاى سينتيكى رشد و توليد بررسى شده است و تطابق

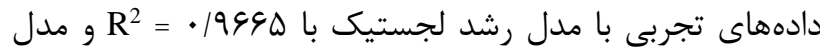

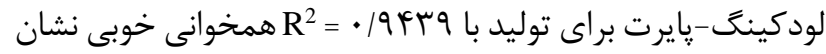
داده است. طبق منحنى ترسيم شده روز دهم به علت دارا بودن بإن بيشترين مقدار وزن خشك سلولى و CGC انتخاب شده است.

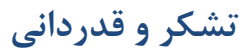

اين تحقيق حاصل يايان نامه دانشجويى كارشناسى ارشد باكد

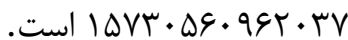

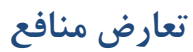

بين نويسندكان تعارض منافع كزارش نشده است.

\section{Referance}

1. Singh A, Dutta PK, Kumar H, Kureel AK, Rai AK. Synthesis of chitin-glucan-aldehyde-quercetin conjugate and evaluation of anticancer and antioxidant activities.

Carbohydr Polym.

2018;193:99-107. [DOI:10.1016/j.carbpol.2018.03.092] [PMID]
مى توانند به عنوان يك منبع اميدوار كننده از كيتوسان با خواص

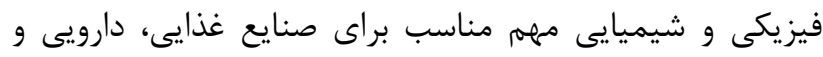

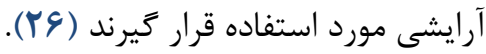

مىتوان كفت مطالعه حاضر با مطالعات Amorim و Feofilova

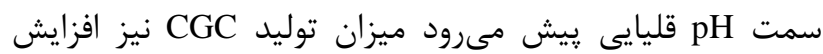

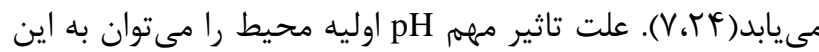
صورت توجيه نمود كه pH محيط مىتواند روى عملكرد غشاء، مورفولوزى سلول، جذب مواد غذايى و توليد محصولات برون

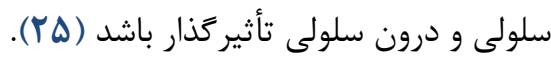

ضريب ويزه رشد قارج شيزوفيلوم كومينه بومى ايران (

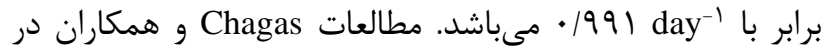

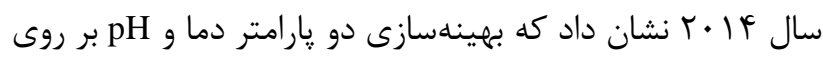
شرايط رشد و توليد محصول CGC از مخمر بيكيا بإستورى بإن

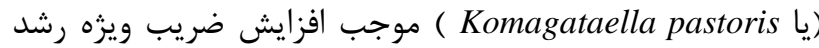

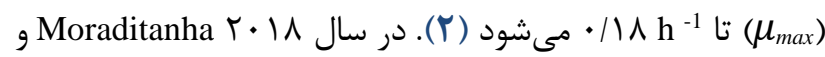
همكاران به مطالعه سينتيك رشد و توليد كميلكس كيتينكلوكان از قارج دارويى كنودرما لوسيديوم در محيط كشت غوطه ور يرداختند. يُ از بر برسى تغييرات وزن خشك سلولى و CGC استخراجى در طى بازه زمانى 19 روزه، ضريب ويزه رشد رئل به ميزان ويزه رشد به دست آمده، قارج شيزوفيلوم كومينه داراى رشد و توليد CGC سريعترى نسبت به كنودرما لوسيد يوم است. قارجها شكلهاى مورفولوزى مختلفى را در محيط كشت

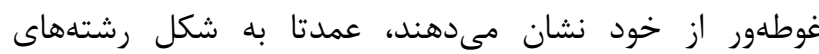
ميسليومى يراكنده (فيلامنتوس) و تودههاى درهم بافته حجيم آنمان

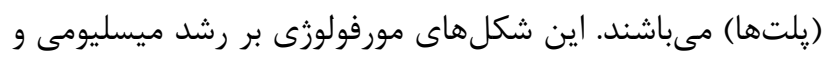

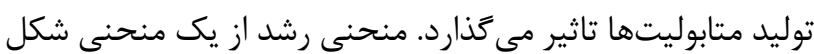

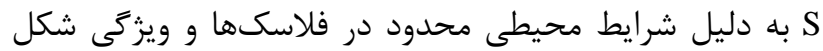

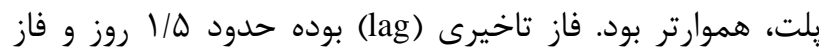

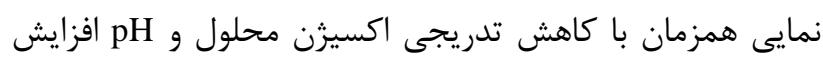

2. Chagas B, Farinha I, Galinha CF, Freitas F, Reis MAM. Chitin-glucan complex production by Komagataella (Pichia) pastoris: Impact of cultivation $\mathrm{pH}$ and temperature on polymer content and composition. $\mathrm{N}$ Biotechnol. 2014;31(5):468-74. [DOI:10.1016/j.nbt.2014.06.005] [PMID] 
3. Vysotskaya MR, Maslova G V., Petrova VA, Nud'ga LA. Electrochemical recovery of chitin-glucan complex from Pleurotus ostreatus basidial fungus and properties of the product. Russ J Appl Chem. 2009;82(8):1390-5. [DOI:10.1134/S1070427209080138]

4. Gautier S, Xhauflaire-Uhoda E, Gonry P, Piérard GE. Chitin-glucan, a natural cell scaffold for skin moisturization and rejuvenation. Int $\mathbf{J}$ Cosmet Sci. 2008;30(6):459-69.

[DOI:10.1111/j.14682494.2008.00470.x] [PMID]

5. Kirtzel J, Scherwietes EL, Merten D, Krause K, Kothe E. Metal release and sequestration from black slate mediated by a laccase of Schizophyllum commune. Environ Sci Pollut Res. 2019;26(1):5-13. [DOI:10.1007/s11356-0182568-z] [PMID]

6. Farinha I, Duarte P, Pimentel A, Plotnikova E, Chagas B, Mafra L, et al. Chitin-glucan complex production by Komagataella pastoris: Downstream optimization and product characterization. Carbohydr Polym. 2015 Oct 5;130:455-64. [DOI:10.1016/j.carbpol.2015.05.034] [PMID]

7. Feofilova EP, Nemtsev D V., Tereshina VM, Memorskaya AS. Developmental change of the composition and content of the chitin-glucan complex in the fungus Aspergillus niger. Appl Biochem Microbiol. 2006;42(6):545-9. [DOI:10.1134/S0003683806060032]

8. Du B, Zeng H, Yang Y, Bian Z, Xu B. Anti-inflammatory activity of polysaccharide from Schizophyllum commune as affected by ultrasonication. Int $\mathbf{J}$ Biol Macromol. 2016;91:100-5. [DOI:10.1016/j.ijbiomac.2016.05.052] [PMID]

9. Sornlake W, Rattanaphanjak P, Champreda V, Eurwilaichitr L, Kittisenachai S, Roytrakul S, et al. Characterization of cellulolytic enzyme system of Schizophyllum commune mutant and evaluation of its efficiency on biomass hydrolysis. Biosci Biotechnol Biochem. 2017;81(7):1289-99. [DOI:10.1080/09168451.2017.1320937] [PMID]

10. Abdel-Mohsen AM, Jancar J, Massoud D, Fohlerova Z, Elhadidy H, Spotz Z, et al. Novel chitin/chitosan-glucan wound dressing: Isolation, characterization, antibacterial activity and wound healing properties. Int J Pharm. 2016 Aug [DOI:10.1016/j.ijpharm.2016.06.003] [PMID]

11. Estrada-Mata E, Navarro-Arias MJ, Pérez-García LA, Mellado-Mojica E, López MG, Csonka K, et al. Members of the Candida parapsilosis complex and Candida albicans are differentially recognized by human peripheral blood mononuclear cells. Front Microbiol. 2016;6(JAN):1-11. [DOI:10.3389/fmicb.2015.01527] [PMID] [PMCID]

12. Farinha I, Duarte P, Pimentel A, Plotnikova E, Chagas B, Mafra L, et al. Chitin-glucan complex production by Komagataella pastoris: Downstream optimization and product characterization. Carbohydr Polym. 2015 Oct

\section{$5 ; 130: 455-64$ [PMID] \\ [DOI:10.1016/j.carbpol.2015.05.034]}

13. Nwe N, Stevens WF, Tokura S, Tamura H. Characterization of chitosan and chitosan-glucan complex extracted from the cell wall of fungus Gongronella butleri USDB 0201 by enzymatic method. Enzyme Microb Technol. $2008 \quad$ Feb 4;42(3):242-51. [DOI:10.1016/j.enzmictec.2007.10.001]

14. Li W, Zhou P, Yu L. Statistical optimization of the medium composition by response surface methodology to enhance schizophyllan production by Schizophyllum commune. Zeitschrift fur Naturforsch - Sect C J Biosci. 2011;66 C(3-4):173-81. [DOI:10.1515/znc-2011-3-412] [PMID]

15. Jonathan SG, Fasidi IO. Studies on phytohormones, vitamins and mineral element requirements of Lentinus subnudus (Berk) and schizophyllum commune (Fr. Ex. Fr) from Nigeria. Food Chem. 2001;75(3):303-7. [DOI:10.1016/S0308-8146(01)00154-6]

16. Bowman SM, Free SJ. The structure and synthesis of the fungal cell wall. 2006;799-808. [DOI:10.1002/bies.20441] [PMID]

17. Hao LM, Xing XH, Li Z, Zhang JC, Sun JX, Jia SR, et al. Optimization of effect factors for mycelial growth and exopolysaccharide production by schizophyllum commune. In: Applied Biochemistry and Biotechnology. 2010. p. 621-31. [DOI:10.1007/s12010-008-8507-6] [PMID]

18. Society P, Microbiologists OF. P O L S K I E T O WA R Z Y S T W O M I K R O B I O L O G Ó W Polish Journal of Microbiology. 2011;57(1):223-8.

19. Meichik NR, Vorob'ev D V. Chitin-glucan complex in cell walls of the Peltigera aphthosa lichen. Appl Biochem Microbiol. 2012;48(3):307-11 [DOI:10.1134/S0003683812030088]

20. Ordonñez L, Garciía J, Bolanños G. Producing chitin and chitin-glucan complexes from Aspergillus niger biomass using subcritical water. InProceedings of the Iberoamerican Conference on Supercritical Fluids, Cartagena, Colombia 2013 Apr (pp. 1-5).

21. Veverka M, Dubaj T, Gallovič J, Jorík V, Veverková E, Mičušík M, et al. Beta-glucan complexes with selected nutraceuticals: Synthesis, characterization, and stability. J Funct Foods. 2014;8(1):309-18. [DOI:10.1016/j.jff.2014.03.032]

22. Moraditanha A, HatamianZarmi A, EbrshimiHoseinZade B, BeigomMokhtariHoseini Z, KianiRad S. Study of growth kinetics and production of chitin-glucans complex in drug-immersed cultivation of medicinal fungi Ganoderma lucidum. Interdiscip J Sci Res. 2018;2(1):3143. [In Persian]

23. Tajdini F, Amini MA, Nafissi-Varcheh N, Faramarzi MA. Production, physiochemical and antimicrobial properties of fungal chitosan from Rhizomucor miehei and Mucor 
racemosus. Int J Biol Macromol. 2010 Aug 1;47(2):180-3. [DOI:10.1016/j.ijbiomac.2010.05.002] [PMID]

24. Amorim RV da S, Souza W de, Fukushima K, CamposTakaki GM de. Faster Chitosan Production By Mucoralean Strains. J Microbiol. 2001;(1517-8382):20-3. [DOI:10.1590/S1517-83822001000100005]

25. Chen W, Zhao Z, Chen SF, Li YQ. Optimization for the production of exopolysaccharide from Fomes fomentarius in submerged culture and its antitumor effect in vitro. Bioresour Technol. 2008 May 1;99(8):3187-94. [DOI:10.1016/j.biortech.2007.05.049] [PMID]

26. Abdel-Gawad KM, Hifney AF, Fawzy MA, Gomaa M. Technology optimization of chitosan production from Aspergillus niger biomass and its functional activities. Food Hydrocoll. 2017 Feb 1;63:593-601. [DOI:10.1016/j.foodhyd.2016.10.001]

27. Tang YJ, Zhong JJ. Modeling the kinetics of cell growth and ganoderic acid production in liquid static cultures of the medicinal mushroom Ganoderma lucidum. Biochem. Eng. J. 2004; 21: 259-264. [DOI:10.1016/j.bej.2004.06.008]

28. Feng YL, Li WQ, Wu XQ, Cheng JW, Ma SY. Statistical optimization of media for mycelial growth and exopolysaccharide production by Lentinus edodes and a kinetic model study of two growth morphologies. Biochem. Eng. J. 2010; 49: 104-112. [DOI:10.1016/j.bej.2009.12.002] 